\title{
Influence of Base-Catalyzed Organosolv Fractionation of Larch Wood Sawdust on Fraction Yields and Lignin Properties
}

\author{
Markus Hochegger ${ }^{1}$, Gregor Trimmel ${ }^{2}$, Betty Cottyn-Boitte ${ }^{3}$ (D) Laurent Cézard $^{3}$, Amel Majira ${ }^{3}$, \\ Sigurd Schober ${ }^{1}$ and Martin Mittelbach ${ }^{1, *}$ \\ 1 Institute of Chemistry, NAWI Graz, Central Lab Biobased Materials, University of Graz, 8010 Graz, Austria; \\ markus.hochegger@uni-graz.at (M.H.); si.schober@uni-graz.at (S.S.) \\ 2 Institute for Chemistry and Technology of Materials (ICTM), NAWI Graz, Graz University of Technology, \\ 8010 Graz, Austria; gregor.trimmel@tugraz.at \\ 3 Institut Jean-Pierre Bourgin, INRA, AgroParisTech, CNRS, Université Paris-Saclay, 78000 Versailles, France; \\ betty.cottyn@inra.fr (B.C.-B.); laurent.cezard@inra.fr (L.C.); amel.majira@versailles.inra.fr (A.M.) \\ * Correspondence: martin.mittelbach@uni-graz.at; Tel.: +43316380-5353
}

Received: 30 October 2019; Accepted: 25 November 2019; Published: 27 November 2019

\begin{abstract}
Lignocellulose-based biorefineries are considered to play a crucial role in reducing fossil-fuel dependency. As of now, the fractionation is still the most difficult step of the whole process. The objective of this study is to investigate the potential of a base-catalyzed organosolv process as a fractionation technique for European larch sawdust. A solvent system comprising methanol, water, sodium hydroxide as catalyst, and anthraquinone as co-catalyst is tested. The influence of three independent process variables, temperature (443-446 K), catalyst loading (20-30\% w/w), and alcohol-to-water ratio $(30-70 \% v / v)$, is studied. The process conditions were determined using a fractional factorial experiment. One star point $(443 \mathrm{~K}, 30 \% v / v \mathrm{MeOH}, 30 \% w / w \mathrm{NaOH})$ resulted in the most promising results, with a cellulose recovery of $89 \%$, delignification efficiency of $91 \%$, pure lignin yield of $82 \%$, residual carbohydrate content of $2.98 \% w / w$, and an ash content of $1.24 \%$ $w / w$. The isolated lignin fractions show promising glass transition temperatures $(\geq 424 \mathrm{~K})$ with high thermal stabilities and preferential $\mathrm{O} / \mathrm{C}$ and $\mathrm{H} / \mathrm{C}$ ratios. This, together with high contents of phenolic hydroxyl ( $\geq 1.83 \mathrm{mmol} / \mathrm{g}$ ) and carboxyl groups $(\geq 0.52 \mathrm{mmol} / \mathrm{g})$, indicates a high valorization potential. Additionally, Bjorkman lignin was isolated, and two reference Kraft cooks and a comparison to three acid-catalyzed organosolv fractionations were conducted.
\end{abstract}

Keywords: lignin; organosolv; fractionation; European larch; characterization

\section{Introduction}

Interest in renewable resources to supply energy and products significantly increased over the last 20 years. The driving factors of this trend are the reduction of fossil-fuel dependence, sustainability, mitigation of greenhouse gas emissions, and the ever-increasing global energy demand. Lignocellulosic biorefineries will play a key role in achieving these goals, as they are able to generate chemicals, fuels, and energy from non-feed/food biomass such as primary wood processing (e.g., wood chips and sawdust) [1,2].

The pretreatment step of lignocellulosic biomass is one of the crucial steps of biomass valorization, as well as one of the most cost-intensive, accounting for up to $40 \%$ of the total processing costs [1]. A plethora of biological, chemical, physical, and thermal fractionation methods, as well as combinations thereof, were developed to efficiently separate biomass into its main components, cellulose, hemicellulose, and lignin, as well as extractives [1]. For softwoods, sulfite, sulfate, and 
soda pulping are available on a commercial scale; alternative techniques include steam explosion and (auto)catalyzed organosolv pretreatment [3].

The first studies on the organosolv process were published in 1931 by Kleinert and Tayanthal, who found that wood could be delignified using aqueous ethanol at elevated temperature and pressure [4]. Over the years, different solvent systems were tested, including alcohols, ketones, lactones, organic acids, phenols, amines, and various catalysts including acids, bases, and neutral salts [5]. There are two major advantages of organosolv over conventional sulfate and sulfite pulping processes: production of high amounts of valuable side streams/byproducts, such as sulfur-free lignin, and ease of solvent recovery via distillation. The latter is unfortunately only true for simple solvent systems, such as alcohol-water [6].

Recent studies in the field of alcohol based organosolv fractionation of softwoods were mainly performed under acid catalysis. Løhre et al. investigated a two-step semi-continuous process comprising a sulfuric acid-catalyzed organosolv fractionation followed by lignin solvolysis. They used spruce as feedstock and primarily focused on fractionation performance and oil yield [7]. Rossberg et al. investigated the impact of different processing conditions of a sulfuric acid-catalyzed ethanol organosolv process on lignin properties, using spruce, and focusing on downstream processability of the lignin fraction [8]. Nitsos et al. also used spruce to study the effect of sulfuric acid-catalyzed ethanol organosolv pretreatment on fractionation performance and resulting lignin properties, with focus on process performance [9]. Imlauer-Vedoya et al. studied a combined steam explosion and uncatalyzed organosolv process for the fractionation of radiata pine. However, they were only interested in the pulp fraction [10]. Lesar et al. investigated the uncatalyzed ethanol organosolv fractionation of spruce and mixed softwood. They also focused their research on the hydrolyzability of the pulp fraction [11].

A two-stage base-catalyzed organosolv process, named Organocell, was developed in the 1970s in Germany, as an alternative to the Kraft process [12]. In the first step, hemicellulose and part of the lignin fraction are dissolved at elevated temperatures, $443-463 \mathrm{~K}$, in a 1:1 methanol-water mixture. In the second step, the methanol content is reduced ( $30 \% v / v)$ and the chips are cooked with up to $30 \% \mathrm{NaOH}$ on a dry wood basis. Additionally, $0.1 \%-0.2 \%$ anthraquinone $(\mathrm{AQ})$ is added as a redox co-catalyst, to reduce pulp loss and increase delignification efficiency [13]. As the initial step, AQ oxidizes a reducing end of a carbohydrate chain (to form an aldonic acid group), limiting carbohydrate degradation in the process. The in situ formed anthrahydroquinone species then reduces a lignin quinone methide structure, cleaving a $\beta$-aryl ether bond in the process, significantly improving delignification efficiency and reducing lignin condensation reactions [14]. Furthermore, terminal oxidation of primary alcohols to aldehydes leads to extensive lignin fragmentation via retro aldol reactions [13]. The process was also run as a single alkaline step, due to economic considerations [6].

However, to the best of the authors' knowledge, no detailed investigation of fractionation performance and direct comparison to other processes was published; the only available literature to date dealing with the lignin fraction of an Organocell-type pretreatment process is a four-part study by Lindner and Wegener published from 1988 to 1990 [15-18]. In these studies, the lignin fractions from both pulping stages were isolated and analyzed. However, they only investigated the reaction time dependence of these properties and kept all other parameters constant. The isolated lignin fractions had promising properties for valorization, such as low carbohydrate content, relatively low molecular weight, and high content of functional groups; therefore, the authors decided to further investigate this fractionation process.

The aim of this work was to evaluate the potential of a one-step Organocell process using European larch sawdust. The feedstock was chosen due to the high volume of larch timber on the European wood market [19]. The valorization potential of the pulp fraction and the isolated lignin fraction is of major interest. The usability of the lignin fraction mainly depends on the physicochemical properties, as conventional pulping processes, namely, sulfate and sulfite processes, result in technical lignins of low purity that contain sulfur and are highly degraded [20], which reduce the valorization potential significantly. Thus, a high fractionation performance combined with a high-quality lignin 
fraction would significantly increase the attractiveness of the base-catalyzed methanol organosolv process for softwood fractionation. The efficiency of the fractionation was investigated using a fractional factorial design on reaction temperature, catalyst loading, and methanol-to-water ratio. The conditions were derived from literature reporting on the Organocell process [12,15-18]. The results were compared to two lab-scale Kraft processes and three previously reported acid-catalyzed organosolv fractionations [21]. The properties of the resulting lignin fractions were analyzed and compared using ultimate, thermal, ${ }^{31}$ P-NMR, thioacidolysis GC/MS, and HPLC-SEC analysis.

\section{Results and Discussion}

In this publication, the feasibility of a base-catalyzed organosolv treatment with focus on usability of the lignin fraction is explored. In the first part, the fractionation performance is investigated, including purity of the resulting fractions and comparison to two lab-scale Kraft and three acid-catalyzed ethanol organosolv processes from a previous study [21]. In the second part, the physicochemical properties of the isolated lignin fractions are investigated and compared.

\subsection{Feedstock Composition}

The chemical composition of European larch sawdust was determined according to the NREL/TP-510-42618 protocol published by Sluiter et al. [22]. In a previous publication by the authors [21], the composition was determined using a different technique. However, due to the distinctly higher throughput of the protocol described by Sluiter et al. [22], it was analyzed again for a better comparison to the pulp fractions (see Table 1).

Table 1. Composition of European larch, reported as mean $(n=3) \pm$ standard deviation.

\begin{tabular}{|c|c|c|c|c|c|}
\hline & Cellulose & Hemicellulose ${ }^{a}$ & Total Lignin $^{b}$ & Extractives $^{c}$ & Ash [21] \\
\hline $\begin{array}{c}\text { Content } \% \\
w / w\end{array}$ & $42.3 \pm 0.4$ & $29.6 \pm 0.2$ & $26.4 \pm 0.1$ & $2.70 \pm 0.09$ & $0.17 \pm 0.02$ \\
\hline
\end{tabular}

In comparison, Scots pine (Pinus sylvestris) contained a slightly higher amount of cellulose and hemicellulose with $40.0 \%$ and $28.5 \%$ respectively. However, the lignin and extractive contents were both slightly decreased, with $27.7 \%$ and $3.5 \%$, respectively. White spruce (Picea glauca) contained a lower amount of cellulose and extractives, with $39.5 \%$ and $2.1 \%$, respectively. Both the hemicellulose and the lignin content were elevated in comparison, with $30.6 \%$ and $27.7 \%$, respectively [23].

\subsection{Interpretation of Results from Experimental Design}

\subsubsection{Pulp Fraction}

Firstly, preliminary fractionation experiments on alcohol-to-water ratio, type of alcohol used, and concentration of base catalyst were performed in a limited set of combinations (see Supplementary Materials). Based on that, the fractional factorial design of experiment was set up. The quantitative results from the $2^{3-1}$ fractional factorial design are summarized in Table 2. Statistical analyses of the data from the three center point replicates $\left(\mathrm{CP}_{1-3}\right)$ showed that the response to the base-catalyzed organosolv fractionation (BCOS) was reproducible, when comparing lignin and pulp yields, as well as the composition of the respective fractions. The validity of the optimization was limited due to the small number of experiments, as chemical pulping is a rather complex system. Moreover, several responses showed significant curvature (see Supplementary Materials), indicating that a more sophisticated design of experiments, such as response surface methodology, should be used for a proper optimization. However, it was deemed sufficient for an exploratory analysis. 
Table 2. Mass flows for the pulp fraction of the base-catalyzed organosolv fractionation.

\begin{tabular}{cccccccccc}
\hline & \multicolumn{3}{c}{ Parameters $^{\mathbf{a}}$} & \multicolumn{5}{c}{ Pulp Fraction $^{\mathbf{b}}$} \\
\cline { 2 - 9 } & $\boldsymbol{T}$ & $\boldsymbol{S}$ & $\boldsymbol{C}$ & Total & KL $^{\mathbf{c}}$ & ASL & TL & Cellulose & Hemicellulose \\
\hline Sawdust & & & & 100 & 26.07 & 0.35 & 26.42 & 42.34 & 29.56 \\
$\mathrm{SP}_{1}(-/+/-)$ & 443 & 70 & 20 & 54.00 & 4.28 & 0.35 & 4.63 & 37.61 & 11.76 \\
$\mathrm{SP}_{2}(-/-/+)$ & 443 & 30 & 30 & 52.46 & 2.12 & 0.37 & 2.49 & 37.73 & 12.25 \\
$\mathrm{SP}_{3}(+/-/-)$ & 463 & 30 & 20 & 44.69 & 0.35 & 0.20 & 0.55 & 35.12 & 9.02 \\
$\mathrm{SP}_{4}(+/+/+)$ & 463 & 70 & 30 & 34.42 & 0.62 & 0.19 & 0.81 & 26.50 & 7.10 \\
$\mathrm{CP}_{1}(0 / 0 / 0)$ & 453 & 50 & 25 & 45.79 & 0.96 & 0.26 & 1.22 & 34.07 & 10.50 \\
$\mathrm{CP}_{2}(0 / 0 / 0)$ & 453 & 50 & 25 & 46.19 & 0.88 & 0.31 & 1.20 & 34.51 & 10.74 \\
$\mathrm{CP}_{3}(0 / 0 / 0)$ & 453 & 50 & 25 & 46.12 & 0.92 & 0.26 & 1.18 & 34.27 & 10.67 \\
$C P_{1-3}$ & & & & 46.0 & 0.92 & 0.28 & 1.20 & 34.3 & 10.6 \\
$A v g \pm S D$ & & & & 0.2 & 0.03 & 0.02 & 0.02 & 0.2 & 0.1 \\
\hline
\end{tabular}

${ }^{a} T$, cooking temperature (K); $S$, solvent ratio (\% v/v methanol); $C$, catalyst concentration (\% oven-dried wood (odw) $\mathrm{NaOH}) .{ }^{\mathrm{b}}$ All data are yields of components (g) per $100 \mathrm{~g}$ (oven-dried weight) untreated larch sawdust. ${ }^{\mathrm{c}} \mathrm{KL}$, Klason lignin; $A S L$, acid-soluble lignin; TL, total lignin.

Using the Design-Expert 12 software, the major effects of three factors, temperature $\left(X_{1}\right)$, methanol-to-water ratio $\left(X_{2}\right)$, and $\mathrm{NaOH}$ concentration $\left(X_{3}\right)$ on pulp and cellulose yield, as well as residual lignin content, were investigated. These three responses were chosen as they are among the most critical results for an efficient fractionation. The Shapiro-Wilk test was used to test for normality. ANOVA and multiple linear regression analysis were used to determine if the effects were either positive or negative [24] (see Supplementary Materials). Only the residual lignin content did not follow a normal distribution $(\alpha<0.05)$. Except for the methanol $(\mathrm{MeOH}) / \mathrm{H}_{2} \mathrm{O}$ ratio in the case of residual lignin content, all factors had a negative effect. Pareto charts were drawn to visualize the magnitude and importance of the effects. Additionally, the linear correlation coefficients of the three coded factors on each response were plotted, to visualize the significance of the respective effects (see Figures 1 and 2). As can be seen in both figures, all three factors had a significant influence on the response. Temperature, as already indicated by the preliminary experiments (see Supplementary Materials), indeed had the greatest impact, especially for cellulose and lignin yield. Interestingly, catalyst loading and $\mathrm{MeOH} / \mathrm{H}_{2} \mathrm{O}$ ratio had, on average, similar magnitudes of effect over all responses. These data clearly show that a delicate balance of catalyst loading, $\mathrm{MeOH} / \mathrm{H}_{2} \mathrm{O}$ ratio, and temperature has to be found for optimal fractionation performance, since the effect of both delignification and cellulose degradation is positive, albeit with different magnitudes. However, as the effect of the $\mathrm{MeOH} / \mathrm{H}_{2} \mathrm{O}$ ratio is inverse for delignification and cellulose degradation, a low $\mathrm{MeOH}$ content is to be preferred for maximum fractionation performance.
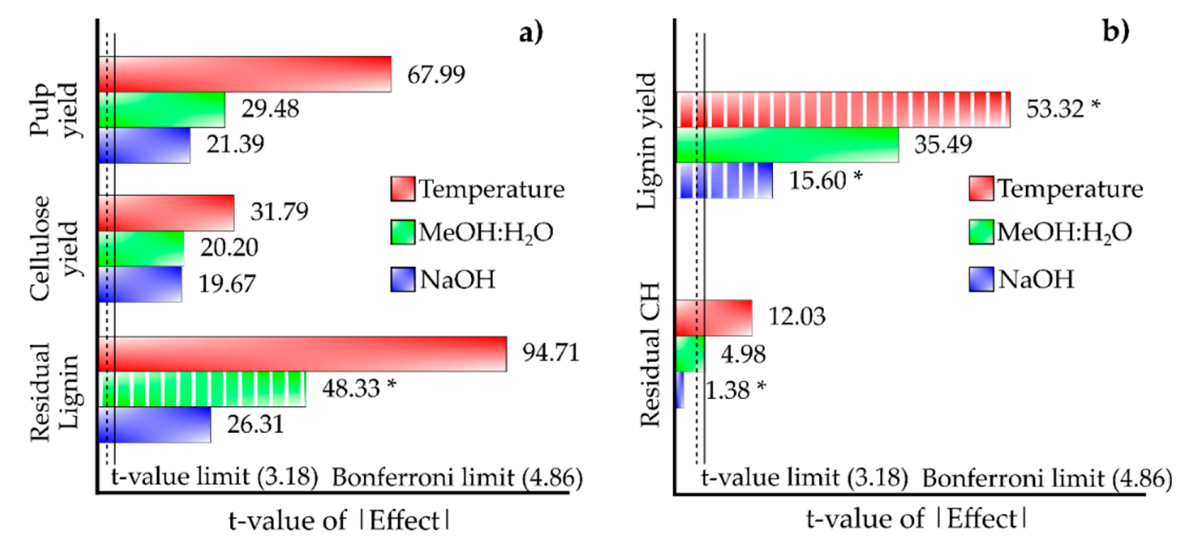

Figure 1. Pareto charts showing the effect of temperature, methanol $(\mathrm{MeOH}) / \mathrm{H}_{2} \mathrm{O}$ ratio, and $\mathrm{NaOH}$ concentration on the respective responses. (a) Responses of the pulp fraction; (b) responses of the lignin fraction. On the $x$-axis, the square roots of the $F$-values from the ANOVA analysis are plotted. Factors denoted with an asterisk and dashed lines are positive, while all others are negative. The $t$-value limit (line of significance) is denoted by a dashed line, whereas the Bonferroni limit (absolute significance) by a solid line. 


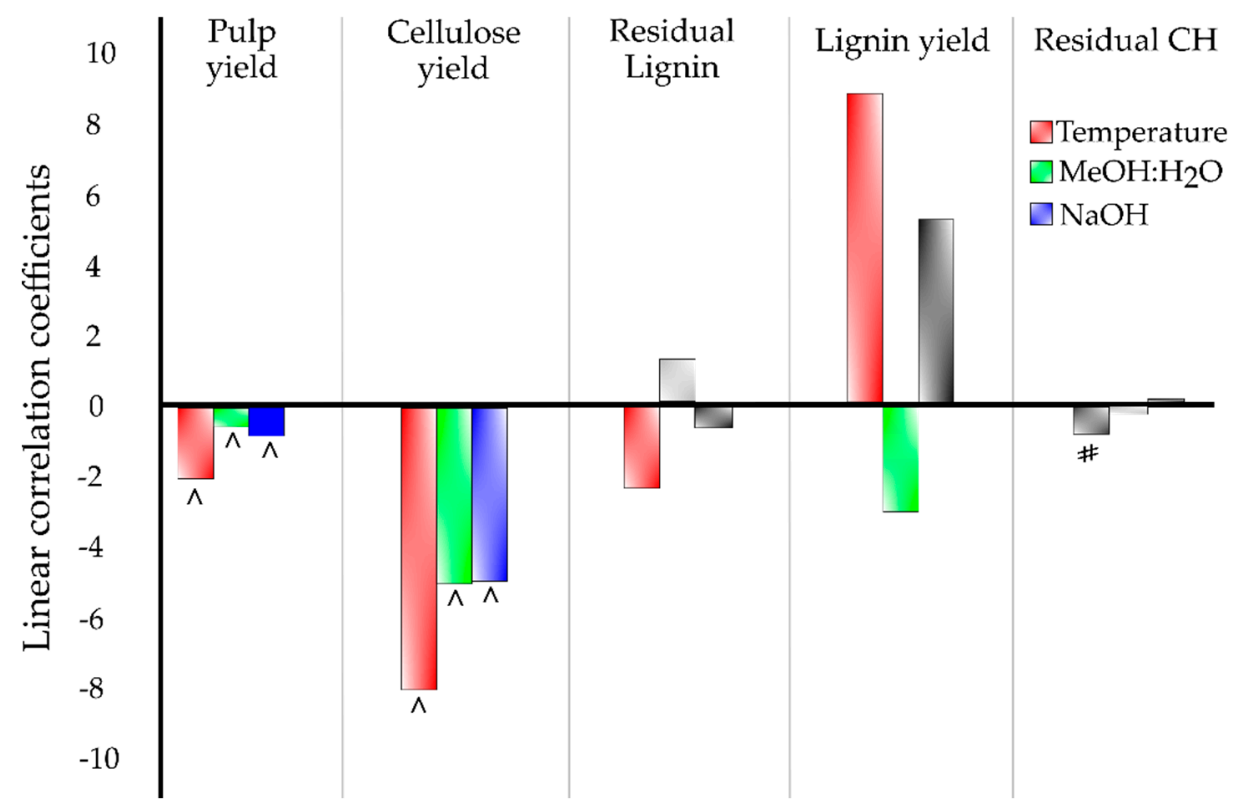

Figure 2. Effects of the three factors, temperature, $\mathrm{MeOH} / \mathrm{H}_{2} \mathrm{O}$ ratio, and $\mathrm{NaOH}$ concentration, on the responses of pulp, cellulose, and lignin yield, as well as residual lignin and residual carbohydrate $(\mathrm{CH})$ content. The responses are increased/decreased by positive/negative correlation coefficients, respectively. Colored bars have a significant correlation at $p=0.05$, bars with ^ have a significant correlation at $p=0.01$. \# denotes a significant effect at $p=0.10$. The linear correlation coefficients are derived from multiple linear regression analysis (see Supplementary Materials).

The lowest amount of residual lignin in the pulp fraction was achieved under $\mathrm{SP}_{3}$ conditions $(463 \mathrm{~K}, 30 \% v / v \mathrm{MeOH}$, and $20 \% w / w \mathrm{NaOH})$ with $1.23 \%$ Klason lignin (2.07\% of initial wood content) (see Table 2). The pulp and cellulose yields of $44.69 \%$ oven-dried wood (odw) and $82.96 \%$ initial wood (i.w.), respectively, were comparable to center point conditions but were significantly lower compared to the reactions performed at $443 \mathrm{~K}\left(\mathrm{SP}_{1}, \mathrm{SP}_{2}\right)$ (see Table 2). Pulping run $\mathrm{SP}_{4}$ was given the maximum values of all variables. These maximum conditions significantly decreased the pulp and cellulose recovery, resulting in the lowest yields of this study, with $46.74 \%$ i.w. and $62.59 \%$ i.w., respectively. Additionally, the delignification efficiency was reduced compared to $\mathrm{SP}_{3}$, making these experimental conditions unfeasible.

Although being less efficient than $\mathrm{SP}_{3}$ in terms of raw fractionation performance, the authors decided that the conditions of $\mathrm{SP}_{2}$ resulted in the most preferential results. Cellulose recovery was excellent at $89 \%$, with a delignification efficiency of $91 \%$. It was deduced from a publication by van Tran [25] that, after bleaching via oxygen delignification to the same residual lignin content as $\mathrm{SP}_{3}$, the expected pulp yield would still be significantly higher, with an estimated $68 \%$ i.w. versus $61 \%$ i.w. It also would not significantly impair the physical properties of the pulp fraction according to Yang et al. [26].

As can be seen in all tested experimental conditions (see Table 2), the presence of anthraquinone hindered efficient hemicellulose removal. This was expected, since anthraquinone (AQ) protects the reducing sugar ends groups via oxidation to aldonic acid groups [14]. For a proper hemicellulose removal, the authors suggest either a pre- or a post-pulping hydrolysis step at elevated temperatures. The former concept was used in the two-step Organocell process, the basis for the investigations in this study [12]. However, recently, it was demonstrated by Borrega et al. [27] that a post-pulping hydrolysis step increases both cellulose yield and purity in comparison to pre-pulping hydrolysis in traditional Kraft pulps. Possible high-value applications for the pulp fraction, due to the high cellulose and low lignin content, after hemicellulose removal and possible bleaching, include cellulose nanofibers [28,29] and dissolving pulp preparation [6]. 
Higher fractionation efficiency in comparison to catalyzed ethanol organosolv pulping

Both Kraft processes were performed at a lower liquid-to-solid ratio of 3.5 versus 8 . Therefore, the solid loading was increased to $40 \mathrm{~g}$ oven-dried wood, to reach the solvent level required for adequate mixing in the stirred batch reactor.

The low-severity Kraft process (Kraft (-)) was the least efficient fractionation process tested in this study, resulting in a delignification efficiency of just $78.95 \%$ (see Table 3). The conditions were chosen, as reaction temperature $(440 \mathrm{~K}$ vs. $443 \mathrm{~K})$, residence time (58 $\mathrm{min}$ vs. $60 \mathrm{~min}$ ), and effective alkali charge ( $19 \%$ odw vs. $20 \%$ odw) were almost identical to $\mathrm{SP}_{1}$. Compared to that, the pulp and cellulose yields were similar, albeit slightly lower. Hemicellulose recovery was distinctly decreased for the low-severity Kraft process, which was expected due to the protective properties of anthraquinone, which is detrimental for an efficient hemicellulose removal. As expected, pulp, cellulose, and hemicellulose yields, as well as residual lignin content, were significantly lower for the high-severity Kraft process (see Table 3). The residual lignin content was comparable to that of $\mathrm{SP}_{2}(8.61 \%$ i.w. vs. $9.36 \%$ i.w.); however, the cellulose and hemicellulose yields were significantly decreased, closer to that of $\mathrm{SP}_{3}$, albeit slightly lower. Comparing the Kraft cooks of this study to the results by Hörhammer et al. [30] on Siberian larch, significantly higher pulp yields were achieved for the low-severity pulping run, with $52.1 \% w / w$ vs. $43.2 \% w / w$. This also coincided with a higher kappa number, 50.3 vs. 67.1 , which was calculated using a previously published approximation (\% Klason lignin $=0.159 \times$ kappa number) [6]. The kappa number is an indicator for bleachability and degree of delignification for pulp samples and is based on the reaction of a $0.1 \mathrm{~N}$ potassium permanganate solution with lignin [6]. This trend can be also seen in the high-severity process, albeit distinctly less pronounced, with $42.8 \% w / w$ vs. $40.2 \% w / w$ and 33.4 vs. 24.2 , respectively. These results indicate a significantly poorer fractionation performance of the Kraft processes in this study, which can be attributed to lower humidity $(40 \% w / w$ vs. $21 \% w / w)$, poorer mixing, and difference in feedstock composition.

Table 3. Mass flows for the Kraft and acid-catalyzed organosolv fractionations.

\begin{tabular}{|c|c|c|c|c|c|c|c|c|c|c|c|}
\hline & \multicolumn{5}{|c|}{ Pulp Fraction ${ }^{a}$} & \multicolumn{6}{|c|}{ Lignin Fraction } \\
\hline & Total & $\mathrm{KL}^{\mathrm{b}}$ & ASL & Cell & Hcell & Total & KL & ASL & TL & $\mathrm{CH}$ & Ash \\
\hline Sawdust & 100 & 26.07 & 0.35 & 42.34 & 29.56 & - & - & - & - & - & - \\
\hline Kraft (-) & 52.08 & 4.84 & 0.72 & 36.86 & 9.66 & 23.27 & 19.14 & 0.35 & 19.50 & 0.51 & 0.56 \\
\hline Kraft (+) & 42.83 & 1.98 & 0.29 & 33.05 & 7.51 & 26.90 & 22.76 & 0.55 & 23.31 & 0.46 & 0.68 \\
\hline $\operatorname{EOS}(-)^{c}$ & 47.79 & 8.45 & 0.18 & 36.98 & 2.23 & 16.36 & 15.48 & 0.07 & 15.55 & 0.09 & $>0.05$ \\
\hline $\operatorname{EOS}(0)$ & 38.56 & 4.91 & 0.15 & 32.84 & 0.67 & 19.42 & 18.12 & 0.15 & 18.27 & 0.08 & $>0.05$ \\
\hline $\operatorname{EOS}(+)$ & 29.74 & 5.31 & 0.12 & 24.05 & 0.27 & 20.83 & 19.52 & 0.24 & 19.78 & 0.18 & $>0.05$ \\
\hline
\end{tabular}

${ }^{a}$ Data are yields of components $(\mathrm{g})$ per $100 \mathrm{~g}$ (oven-dried weight) untreated larch sawdust. ${ }^{\mathrm{b}}$ EOS, ethanol organosolv; KL, Klason lignin; $A S L$, acid-soluble lignin; Cell, cellulose; Hcell, hemicellulose; $T L$, total lignin; $C H$, residual carbohydrates. ' Sulfuric acid loading, reaction time, and liquid-to-solid ratio were set to $1.10 \%$ odw, 30 $\mathrm{min}$, and $7 \mathrm{v} / \mathrm{w}$, respectively; reaction temperatures were $440 \mathrm{~K}(-), 450 \mathrm{~K}(0)$, and $460 \mathrm{~K}(+)$, respectively.

Higher fractionation efficiency in comparison to catalyzed ethanol organosolv pulping

To be able to better assess the fractionation performance of the base-catalyzed organosolv process, three pulp and corresponding lignin samples were included that were isolated in a previous study on acid-catalyzed ethanol organosolv fractionation of the same feedstock [21].

The most distinct difference between the results of the acid-catalyzed organosolv fractionation and both base-catalyzed processes was obviously hemicellulose yield, as hemicellulose is significantly more susceptible toward acid hydrolysis [31]. Even in low-severity conditions, the hemicellulose content of the pulp fraction was just $7.52 \%$ of initial wood content, compared to $24.02 \%$ i.w. for the most severe base-catalyzed organosolv process $\left(\mathrm{SP}_{4}\right)$ (see Table 3). On the downside, with increasing temperature (440-460 K), the cellulose yield decreased significantly, from $87.33 \%$ i.w. to $56.80 \%$ i.w., dropping to levels lower than that of $\mathrm{SP}_{4}(62.59 \%$ i.w.). At the same time, the residual lignin content did not 
decrease accordingly, with a minimal content of $19.02 \%$ i.w., only being able to surpass the least efficient base-catalyzed process in terms of fractionation performance (Kraft low, 21.05\% i.w.). Additionally, at $460 \mathrm{~K}$, pseudo-lignin formation likely occurred, increasing the Klason lignin content. Pseudo-lignins are aromatic compounds that are hypothesized to form from carbohydrate degradation products, such as 5-hydroxymethylfurfural (C6 sugars) and furfural (C5 sugars) via a series of rearrangement, oxidation, polymerization, and condensation reactions $[32,33]$.

\subsubsection{Lignin Fraction}

Lignin isolation yields must also be considered when deciding the optimum process conditions of a lignocellulosic biomass fractionation process. The pure lignin yields ranged from $64.7 \%\left(\mathrm{SP}_{1}\right)$ to $88.0 \%\left(\mathrm{SP}_{3}\right)$ of initial wood content (i.w.) (see Table 4). As expected, the maximum yield coincided with the lowest residual lignin content of the pulp fraction $\left(\mathrm{SP}_{3}\right)$ and vice versa $\left(\mathrm{SP}_{1}\right)$. The main factor affecting lignin yield was temperature, having a positive effect according to ANOVA analysis (see Figures 1 and 2). The methanol-to-water ratio had the second biggest effect, correlating negatively to lignin yield. The average of lignin purity, including all tested reaction conditions, was $93.7 \% \pm 0.2 \%$ $w / w$. The $t$-value of effect for all three factors $\left(X_{1}-X_{3}\right)$ failed to reach the $t$-value limit, suggesting their independence (not shown). Impurities of the lignin fractions included not only residual carbohydrates and ash but also residual water, as well as water/diluted methanol-insoluble wood extractives/resins and degradation products. The latter two only reduce apparent purity if they either decompose or evaporate at $378 \mathrm{~K}$; they contribute to the acid-insoluble lignin fraction otherwise. The content of residual carbohydrates was low for each lignin fraction, ranging from $2.98 \% w / w\left(\mathrm{SP}_{2}\right)$ to $0.76 \%$ $w / w\left(\mathrm{SP}_{4}\right)$. Interestingly, temperature was the only factor having a significant effect on the residual carbohydrate content of the lignin fraction, correlating negatively to it (see Figures 1 and 2). The $t$-value of the effect of $\mathrm{MeOH} / \mathrm{H}_{2} \mathrm{O}$ ratio barely exceeded the Bonferroni limit, and that of $\mathrm{NaOH}$ concentration did not even reach the $t$-value limit. The ash content of all lignin fractions was low as well, ranging from just $0.53 \% w / w$ to $1.24 \% w / w$. The ash content was only determined by the initial base loading and the washing efficiency during work-up.

Table 4. Mass flows for the lignin fractions of the base-catalyzed organosolv fractionations.

\begin{tabular}{cccccccc}
\hline & \multicolumn{9}{c}{ Lignin Fraction ${ }^{\text {a }}$} & & Aqueous Fraction \\
\cline { 2 - 7 } & Total & KL & ASL & TL & CH & Ash & ASL \\
\hline $\mathrm{SP}_{1}(-/+/-)$ & 18.44 & 16.78 & 0.56 & 17.34 & 0.40 & 0.10 & 4.56 \\
$\mathrm{SP}_{2}(-/-/+)$ & 21.53 & 19.57 & 0.62 & 20.19 & 0.64 & 0.27 & 3.94 \\
$\mathrm{SP}_{3}(+/-/-)$ & 24.82 & 22.38 & 0.87 & 23.24 & 0.31 & 0.19 & 3.61 \\
$\mathrm{SP}_{4}(+/+/+)$ & 23.08 & 21.07 & 0.52 & 21.59 & 0.18 & 0.28 & 7.06 \\
$\mathrm{CP}_{1}(0 / 0 / 0)$ & 22.28 & 20.01 & 0.65 & 20.66 & 0.28 & 0.23 & 5.63 \\
$\mathrm{CP}_{2}(0 / 0 / 0)$ & 22.16 & 20.24 & 0.58 & 20.82 & 0.22 & 0.24 & 5.62 \\
$\mathrm{CP}_{3}(0 / 0 / 0)$ & 22.57 & 20.42 & 0.67 & 21.10 & 0.25 & 0.25 & 5.62 \\
$C P_{1-3}$ & 22.3 & 20.2 & 0.64 & 20.9 & 0.25 & 0.24 & 5.62 \\
$A v g \pm S D$ & 0.2 & 0.1 & 0.05 & 0.2 & 0.03 & 0.01 & 0.01 \\
\hline
\end{tabular}

${ }^{\mathrm{a}}$ Data are yields of components (g) per $100 \mathrm{~g}$ (oven-dried weight) untreated larch sawdust.

The mass balances for lignin for the base-catalyzed organosolv fractionations are shown in Table 5 . Note that the lignin recoveries were all over $100 \%$, except for the two experiments performed at lower temperatures $(443 \mathrm{~K})$. This can be attributed to the more excessive carbohydrate degradation at higher temperatures that can lead to overestimation of the acid-soluble lignin content of the aqueous fraction. Additionally, the presence of $2.70 \% w / w$ acetone extractives in European larch wood further complicated the exact determination, as they can influence both Klason lignin and acid-soluble lignin content [34]. 
Table 5. Lignin recovery for the base-catalyzed organosolv fractionations.

\begin{tabular}{ccccccc}
\hline & \multicolumn{2}{c}{ Pulp Fraction a } & \multicolumn{2}{c}{ Lignin Fraction } & $\begin{array}{c}\text { Aqueous } \\
\text { Fraction }\end{array}$ & $\begin{array}{c}\text { Lignin } \\
\text { Recovery }\end{array}$ \\
\cline { 2 - 7 } & KL & ASL & KL & ASL & ASL & \% \\
\hline $\mathrm{SP}_{1}(-/+/-)$ & 4.28 & 0.35 & 16.78 & 0.56 & 4.56 & 100.4 \\
$\mathrm{SP}_{2}(-/-/+)$ & 2.12 & 0.37 & 19.57 & 0.62 & 3.94 & 100.8 \\
$\mathrm{SP}_{3}(+/-/-)$ & 0.35 & 0.20 & 22.38 & 0.87 & 3.61 & 103.8 \\
$\mathrm{SP}_{4}(+/+/+)$ & 0.62 & 0.19 & 21.07 & 0.52 & 7.06 & 111.5 \\
$\mathrm{CP}_{1}(0 / 0 / 0)$ & 0.96 & 0.26 & 20.01 & 0.65 & 5.63 & 104.1 \\
$\mathrm{CP}_{2}(0 / 0 / 0)$ & 0.88 & 0.31 & 20.24 & 0.58 & 5.62 & 104.6 \\
$\mathrm{CP}_{3}(0 / 0 / 0)$ & 0.92 & 0.26 & 20.42 & 0.67 & 5.62 & 105.6 \\
$\mathrm{CP}$ & 0.92 & 0.28 & 20.2 & 0.64 & 5.62 & 104.8 \\
$\mathrm{Avg}+\mathrm{SD}$ & 0.03 & 0.02 & 0.1 & 0.05 & 0.01 & 0.5 \\
\hline
\end{tabular}

${ }^{a}$ Data are yields of components (g) per $100 \mathrm{~g}$ (oven-dried weight) untreated larch sawdust

Higher purity compared to Kraft pulping

The pure lignin yields of both Kraft processes were comparatively high, reaching up to $88.24 \%$ i.w., with Kraft $(+)$ being the highest in this study, on par with $\mathrm{SP}_{3}(87.98 \%$ i.w.). The high yields despite lower delignification efficiency can be attributed to the decreased solubility of lignin in pure acidified water compared to acidified $20 \%$ aqueous methanol for the base-catalyzed organosolv fractionations. The purity of both lignin fractions was significantly lower compared to the base-catalyzed organosolv processes, with $83.78 \% w / w(-)$ and $86.67 \% w / w(+)$. The content of residual carbohydrates was low, with $2.21 \% w / w$ and $1.71 \% w / w$, which was similar to the BCOS. The ash content was distinctly higher for both sulfate processes, with $2.21 \% w / w$ and $2.41 \% w / w$ on lignin content. This is to be expected, as (co-)catalyst concentration was between 1.7 and 3.2 times higher based on pulping liquor.

Higher yields compared to catalyzed ethanol organosolv pulping

As expected, lignin yields were lower for the acid-catalyzed process $(61.92 \%-78.84 \%$ i.w.), due to the lower delignification efficiency. However, lignin purity was slightly higher in all three runs (94.08\%-95.6\%), with both lower ash and residual carbohydrate content. The former can be explained by the significantly decreased catalyst loading, whereas the latter due can be explained by the enhanced carbohydrate fragmentation under acidic conditions.

\subsection{Influence of Pulping Conditions on Lignin Properties}

As the second part of this study, the physicochemical properties of the isolated lignin fractions were investigated. They are a key factor for both lignin downstream valorization and feasibility of the whole fractionation process.

\subsubsection{Ultimate Analysis}

The influence of pulping conditions on the elemental composition was determined via ultimate analysis, and the results are shown in Table 6. Both molar hydrogen-to-carbon and oxygen-to-carbon molar ratios can be used as indicators for degrees of aromaticity and of oxygenation, respectively. 
Table 6. Results from ultimate and HPLC-SEC analysis.

\begin{tabular}{|c|c|c|c|c|c|c|c|c|}
\hline & $\begin{array}{c}\mathrm{C} \\
\% w / w\end{array}$ & $\begin{array}{c}\mathbf{H} \\
\% w / w\end{array}$ & $\begin{array}{c}\mathrm{O} \\
\% w / w\end{array}$ & $\begin{array}{c}S \\
\% w / w\end{array}$ & $\begin{array}{c}\mathrm{H} / \mathrm{C} \\
\mathrm{mol} / \mathrm{mol}\end{array}$ & $\begin{array}{c}\mathrm{O} / \mathrm{C} \\
\mathrm{mol} / \mathrm{mol}\end{array}$ & $\begin{array}{c}\mathrm{M}_{\mathrm{n}}{ }^{\mathrm{a}} \\
\mathrm{kg} / \mathrm{mol}\end{array}$ & $\begin{array}{c}\mathrm{M}_{\mathrm{w}} \\
\mathrm{kg} / \mathrm{mol}\end{array}$ \\
\hline MWL & 60.78 & 5.71 & 33.51 & $-b$ & 1.04 & 0.50 & 1.76 & 2.61 \\
\hline $\mathrm{SP}_{1}(-/+/-)$ & 66.13 & 5.78 & 28.09 & - & 1.05 & 0.32 & 1.89 & 2.94 \\
\hline $\mathrm{SP}_{2}(-/-/+)$ & 65.32 & 5.78 & 28.90 & - & 1.06 & 0.33 & 1.80 & 2.88 \\
\hline $\mathrm{SP}_{3}(+/-/-)$ & 66.75 & 5.77 & 27.48 & - & 1.04 & 0.31 & 1.68 & 2.77 \\
\hline $\mathrm{SP}_{4}(+/+/+)$ & 67.27 & 5.85 & 26.88 & - & 1.04 & 0.30 & 1.75 & 2.56 \\
\hline $\mathrm{CP}_{1}(0 / 0 / 0)$ & 66.43 & 5.79 & 27.78 & - & 1.05 & 0.31 & 1.65 & 2.58 \\
\hline $\mathrm{CP}_{2}(0 / 0 / 0)$ & 66.36 & 5.78 & 27.86 & - & 1.05 & 0.31 & 1.62 & 2.52 \\
\hline $\mathrm{CP}_{3}(0 / 0 / 0)$ & 66.27 & 5.82 & 27.91 & - & 1.05 & 0.32 & 1.62 & 2.55 \\
\hline$C P_{1-3}$ & 66.35 & 5.80 & 27.85 & - & 1.05 & 0.31 & 1.63 & 2.55 \\
\hline$A v g \pm S D$ & 0.08 & 0.02 & 0.07 & - & $<0.01$ & $<0.01$ & 0.02 & 0.03 \\
\hline Kraft (-) & 61.78 & 5.33 & 30.23 & 2.66 & 0.99 & 0.44 & 1.81 & 3.05 \\
\hline Kraft (+) & 61.57 & 5.44 & 30.26 & 2.73 & 0.97 & 0.43 & 1.78 & 2.92 \\
\hline $\operatorname{EOS}(-)$ & 66.42 & 6.22 & 27.36 & - & 1.12 & 0.31 & 1.06 & 2.50 \\
\hline $\operatorname{EOS}(0)$ & 66.83 & 5.86 & 27.32 & - & 1.05 & 0.31 & 1.12 & 2.40 \\
\hline $\operatorname{EOS}(+)$ & 67.18 & 6.04 & 26.78 & - & 1.08 & 0.30 & 0.97 & 2.02 \\
\hline
\end{tabular}

${ }^{\mathrm{a}} M_{n}$, number average molecular weight; $M_{w}$, weight average molecular weight. ${ }^{\mathrm{b}}$ Below $0.05 \%$.

All samples were free of nitrogen and, except for both Kraft samples, free of sulfur, which could not be effectively removed with the milled wood lignin (MWL) purification method. Of the tested base-catalyzed organosolv conditions, $\mathrm{SP}_{4}$ produced the lignin fraction with the lowest $\mathrm{H} / \mathrm{C}$ and $\mathrm{O} / \mathrm{C}$ ratios, indicating both severe lignin side-chain degradation and condensation. However, it was recently mentioned by Rossberg et al. [8] that a low $\mathrm{H} / \mathrm{C}$ and $\mathrm{O} / \mathrm{C}$ ratio is desirable for special application such as carbon-fiber production, for which Kraft and soda lignins are frequently used. The Kraft lignin samples isolated in this study had the highest degree of both oxygenation and aromaticity. However, the difference of aromaticity was comparably small. This, together with the high purity, makes the base-catalyzed organosolv samples promising feedstocks for carbon-fiber production. The previously reported acid-catalyzed samples (ethanol organosolv, EOS) [21] had a lower aromaticity with a similar degree of oxygenation. The former was expected, especially for EOS (-), since the fractionation conditions were distinctly less severe.

\subsubsection{Molecular Weight Analysis}

The average molecular weights of the isolated lignin fractions were investigated via size exclusion chromatography (SEC) (see Table 6, Figure 3b). Due to the lack of proper lignin standards, this technique can only provide an estimation on relative molecular mass. Several attempts for a standardization of molecular weight analysis were made previously $[35,36]$. The objective of this investigation was to use the molecular weights (MWs) as an indicator for downstream processability, especially solubility.

As can be seen in Table 6, MWs were not significantly impacted by the pulping conditions. The lowest MWs were achieved under center point conditions, with $1.63 \mathrm{~kg} / \mathrm{mol}$ and $2.55 \mathrm{~kg} / \mathrm{mol}$, respectively, which was just $16 \%$ lower than the maximum $\left(\mathrm{SP}_{1}\right)$. The $\mathrm{M}_{\mathrm{w}}$ range for the acid/base-catalyzed organosolv samples was in agreement with data found in the literature, which also reported lower values for organosolv compared to commercial soda and Kraft processes [8,37-39]. In this study, this was only true for the average molecular weight $\left(M_{n}\right)$ of the acid-catalyzed organosolv samples, whereas the difference in average molecular weight $\left(M_{w}\right)$ was distinctly less pronounced. Interestingly, the heterogeneity $\left(M_{w} / M_{n}\right)$ of the acid-catalyzed organosolv lignins was higher (2.1-2.4) than for the other lignin fractions (1.5-1.7). This might be attributed to the milder fractionation conditions, as less extensive fragmentation of $\beta$-O- 4 bonds occurred, with similar observations being made by others $[40,41]$. All heterogeneities, however, were distinctly lower compared to literature values $[38,39,42]$. Each lignin fraction, regardless of fractionation technique, was still fully soluble in 1,4-dioxane, DMSO, THF, and ethanol/dichloroethane (1:2). 


\subsubsection{Quantitative ${ }^{31} \mathrm{P}-\mathrm{NMR}$ analysis}

${ }^{31}$ P-NMR analysis can be used to distinguish and quantify functional groups of lignin fractions after phosphorylation [43]. In this study, the content of aliphatic and phenolic hydroxyl groups, as well as carboxylic acid groups, was investigated (see Figure 3a). Cyclohexanol was used as an internal standard, despite possible underestimation of hydroxyl groups as reported by Balakshin et al. [44], due to its high stability under the used reaction conditions.
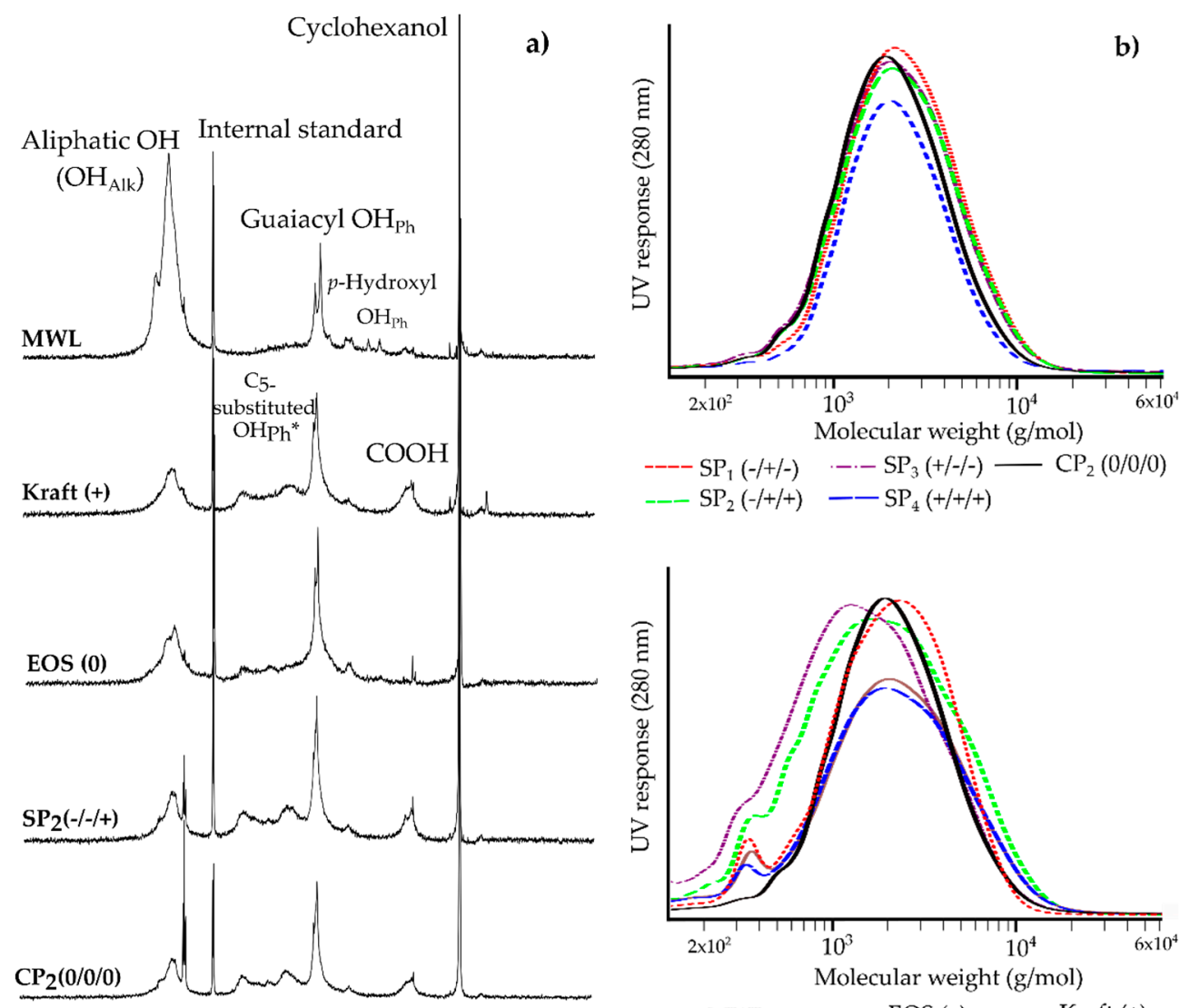

$154152150148146144142140138136134132130128 \mathrm{ppm}$

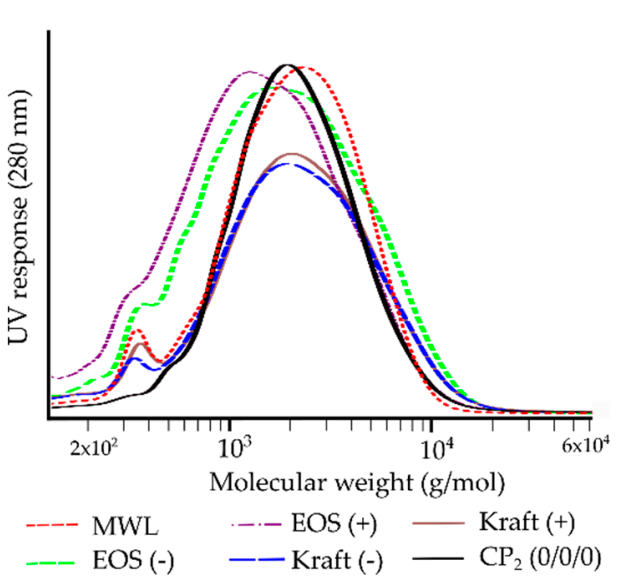

Figure 3. (a) ${ }^{31} \mathrm{P}-\mathrm{NMR}$ spectra of selected lignin samples. The integrals of the $\mathrm{C} 5$-substituted $\mathrm{OH}_{\mathrm{Ph}}$ are added to the integrals of the guaiacyl $\mathrm{OH}_{\mathrm{Ph}}$ to yield the total phenolic hydroxyl groups $\left(\mathrm{OH}_{\mathrm{Ph}}\right)$. (b) Molecular weight distribution of selected lignin samples. Note that $\mathrm{CP}_{2}$ is displayed in both figures to increase comparability.

A distinct decrease in aliphatic hydroxyl groups can be seen in Table 7, when comparing the organosolv and Kraft lignins to the milled wood lignin sample. This indicates that the $\mathrm{OH}_{\text {alk }}$ groups were either cleaved off or chemically modified during the pulping process. The presence of anthraquinone in the base-catalyzed organosolv process favors the oxidation of primary hydroxyl groups to aldehydes, leading to either retro aldol reaction or subsequent oxidation to carboxylic acids. AQ also increases the oxidation of secondary alcohols to ketones, further decreasing $\mathrm{OH}_{\text {alk }}$ [13]. As can be seen in Table 7 , the $\mathrm{OH}_{\text {alk }}$ content for the base-catalyzed organosolv samples was mainly determined by reaction temperature, reaching a minimum of $1.18 \mathrm{mmol} / \mathrm{g}$ at $\mathrm{SP}_{3}$. In roughly comparable pulping conditions $\left(\mathrm{SP}_{1} / \mathrm{Kraft}(-)\right)$ in terms of temperature, time, and effective alkali charge, the Kraft sample contained a slightly lower amount of $\mathrm{OH}_{\text {alk }}$, indicating similar to slightly higher lignin fragmentation in the given conditions. 
Table 7. Results from ${ }^{31} \mathrm{P}-\mathrm{NMR}-$, thioacidolysis GC/MS, and thermal analysis.

\begin{tabular}{|c|c|c|c|c|c|c|c|c|}
\hline & \multicolumn{5}{|c|}{${ }^{31}$ P-NMR Analysis } & \multirow[b]{2}{*}{$\begin{array}{c}\beta-\mathrm{O}-4 \\
\%(\mu \mathrm{mol} / \mathrm{g})\end{array}$} & \multicolumn{2}{|c|}{ Thermal Analysis } \\
\hline & $\begin{array}{c}\mathrm{OH}_{\mathrm{Alk}} \\
\mathrm{mmol} / \mathrm{g}\end{array}$ & $\begin{array}{c}\mathrm{OH}_{\mathrm{Ph}} \\
\mathrm{mmol} / \mathrm{g}\end{array}$ & $\begin{array}{l}\mathrm{OH}_{\text {total }} \\
\mathrm{mmol} / \mathrm{g}\end{array}$ & $\begin{array}{c}\mathrm{Ph} / \mathrm{Alk} \\
\text { ratio }\end{array}$ & $\begin{array}{l}\mathrm{COOH} \\
\mathrm{mmol} / \mathrm{g}\end{array}$ & & $\begin{array}{l}T_{g} \\
K\end{array}$ & $\begin{array}{c}\mathrm{T}_{5 \%} \\
K\end{array}$ \\
\hline $\mathrm{MWL}^{\mathrm{a}}$ & 3.67 & 1.84 & 5.51 & 0.5 & 0.11 & 100 (947) & 432 & 563 \\
\hline $\mathrm{SP}_{1}(-/+/-)$ & 1.54 & 3.47 & 5.01 & 2.3 & 0.43 & $8.2(78)$ & 433 & 496 \\
\hline $\mathrm{SP}_{2}(-/-/+)$ & 1.52 & 3.44 & 4.96 & 2.3 & 0.52 & $4.1(39)$ & 433 & 528 \\
\hline $\mathrm{SP}_{3}(+/-/-)$ & 1.18 & 3.60 & 4.78 & 3.1 & 0.51 & $2.6(25)$ & 429 & 567 \\
\hline $\mathrm{SP}_{4}(+/+/+)$ & 1.38 & 3.83 & 5.21 & 2.8 & 0.47 & $2.7(26)$ & 426 & 578 \\
\hline $\mathrm{CP}_{1}(0 / 0 / 0)$ & 1.51 & 3.68 & 5.19 & 2.4 & 0.50 & $4.6(44)$ & 424 & 497 \\
\hline $\mathrm{CP}_{2}(0 / 0 / 0)$ & 1.54 & 3.69 & 5.23 & 2.4 & 0.50 & $5.0(47)$ & 425 & 512 \\
\hline $\mathrm{CP}_{3}(0 / 0 / 0)$ & 1.59 & 3.78 & 5.37 & 2.4 & 0.52 & $4.8(45)$ & 425 & 483 \\
\hline$C P_{1-3}$ & 1.55 & 3.72 & 5.27 & 2.4 & 0.51 & $4.8(45)$ & 425 & 497 \\
\hline$A v g \pm S D$ & 0.04 & 0.06 & 0.09 & $>0.1$ & 0.01 & $0.2(2)$ & 1 & 14 \\
\hline Kraft (-) & 1.48 & 3.56 & 5.04 & 2.41 & 0.61 & $7.4(70)$ & $-b$ & 473 \\
\hline Kraft $(+)$ & 1.44 & 4.01 & 5.45 & 2.78 & 0.68 & $3.7(35)$ & $-b$ & 412 \\
\hline EOS $(-)$ & 1.92 & 1.78 & 3.70 & 0.9 & 0.09 & $45.8(443)$ & 393 & 512 \\
\hline EOS (0) & 1.61 & 2.35 & 3.96 & 1.5 & 0.07 & $36.8(365)$ & 402 & 516 \\
\hline $\operatorname{EOS}(+)$ & 1.37 & 2.5 & 3.87 & 1.8 & 0.09 & 24.6 (233) & 401 & 471 \\
\hline
\end{tabular}

${ }^{a} \mathrm{MWL}$, milled wood lignin; $\mathrm{OH}_{A l k}$, aliphatic hydroxyl; $\mathrm{OH}_{P h}$, phenolic hydroxyl; $\mathrm{COOH}$, carboxylic acid; $\beta-\mathrm{O}-4$, content of residual $\beta$-O-4 linkages relative to $M W L ; T_{g}$, glass transition temperature, $T_{5 \%}$, temperature at $5 \%$ weight loss. ${ }^{\mathrm{b}}$ No $T_{g}$ detectable.

The content of phenolic hydroxyl groups $\left(\mathrm{OH}_{P h}\right)$ of all isolated lignins was distinctly higher than that of the milled wood lignin sample, due to excessive breaking of ether bonds during the different fractionation processes [31]. Looking at the data shown in Tables 6 and 7, a clear indirect correlation between molecular weight and free phenolic hydroxyl groups can be identified for both catalyzed organosolv processes. Among those, the highest content of $\mathrm{OH}_{P h}, 3.83 \mathrm{mmol} / \mathrm{g}\left(\mathrm{SP}_{4}\right)$, did not coincide with the lowest $\mathrm{M}_{\mathrm{W}}$, indicating a higher degree of lignin condensation. This theory is supported by the fact that both catalyst loading and temperature were the highest for this pulping run. However, the lignin fractions from acid-catalyzed organosolv fractionations displayed significantly lower amounts of $\mathrm{OH}_{\mathrm{Ph}}$. Overall, the Kraft (+) sample had the maximum number of $\mathrm{OH}_{\mathrm{Ph}}$ groups, which was expected due to the high concentration of $\mathrm{Na}_{2} \mathrm{~S}$ and $\mathrm{NaOH}$, leading to excessive lignin fragmentation [20]. When comparing molecular weights and phenolic hydroxyl contents of both Kraft lignins to the base-catalyzed organosolv samples, a lower degree of recondensation at a similar level of fragmentation was indicated for the latter, due to lower MW and reduced $\mathrm{OH}_{p h}$ content. This observation was also supported by a higher $\mathrm{H} / \mathrm{C}$ ratio (see above), making them more promising feedstocks for downstream valorization. The content of phenolic hydroxyl groups for the base-catalyzed organosolv samples from European larch was high compared to other softwood organosolv lignins found in literature. The reported values ranged from 2.6 to $3.5 \mathrm{mmol} / \mathrm{g}$ [8], from 2.44 to $3.64 \mathrm{mmol} / \mathrm{g}$ [9], and $2.99 \mathrm{mmol} / \mathrm{g}$ [42] for spruce, 2.8 $\mathrm{mmol} / \mathrm{g}$ for lodgepole pine [45], and $2.81 \mathrm{mmol} / \mathrm{g}$ for loblolly pine [46].

A distinct increase in carboxylic acid groups can be found for the lignin fractions of the tested Kraft and base-catalyzed organosolv processes. This can be mainly attributed to oxidation of the primary alcohols in the aliphatic side chains $[13,20]$. All three acid-catalyzed lignin fractions displayed a distinctly lower $\mathrm{COOH}$ content, similar to that of the milled wood lignin sample, due to the lower process severity [31]. High amounts of phenolic and carboxyl hydroxyl groups, together with comparably low average molecular weight, make the base-catalyzed organosolv samples promising additives for cellulose nanofiber-starch composite films, which were recently investigated by Zhao et al. [47]. The same properties make them also usable as adhesives for wood panel production, as discussed by Koumba-Yoya et al. [48].

\subsubsection{Thioacidolysis GC/MS Analysis}

As this study serves as a basis for further investigations in this field, thioacidolysis GC/MS was used to quantify the fragmentation of the lignin fraction during the different pulping processes. In 
this method, the aryl ether linkages in the lignin samples were selectively cleaved, derivatized, and quantified via GC/MS. A high content of releasable monomers indicates less lignin degradation and consequently more benign fractionation conditions.

The purified MWL sample of European larch contained a total of $947 \mu \mathrm{mol} / \mathrm{g}$ of releasable monomers, $845 \mu \mathrm{mol} / \mathrm{g}$ G-units, $82 \mu \mathrm{mol} / \mathrm{g}$ vanillic units, and $20 \mu \mathrm{mol} / \mathrm{g} \mathrm{H}$-units, respectively (see Table 6). The former two originated from guaiacyl monomers, while the second was mostly formed via lignin side-chain oxidation that can even occur during mild MWL extraction [31]. H-units are the thioacidolysis derivates of $p$-hydroxyphenyl monomers, which are uncommon in the heartwood lignin of softwood species, but common in bark lignin [49].

As determined by the Design-Expert 12 software, all three factors (temperature, methanol content, $\mathrm{NaOH}$ loading) had a significant impact on the number of residual $\beta$-O-4 linkages, with $\mathrm{MeOH} / \mathrm{H}_{2} \mathrm{O}$ ratio having a positive effect and the other two having a negative effect (not shown). All lignin fractions from both Kraft and base-catalyzed organosolv processes contained less than $10 \%$ of the initial $\beta$-O-4 linkages, demonstrating significant lignin fragmentation (see above). Overall, G-units made up $69-88 \%$ of the total releasable monomers with the rest being vanillic units (see Supplementary Materials). The lowest values for the base-catalyzed samples were achieved under $\mathrm{SP}_{3}$ and $\mathrm{SP}_{4}$ conditions $(2.6 / 2.7 \mu \mathrm{mol} / \mathrm{g})$, which coincided with the highest amount of $\mathrm{OH}_{P h}\left(\mathrm{SP}_{4}\right)$ and lowest amount of $\mathrm{OH}_{\text {alk }}\left(\mathrm{SP}_{3}\right)$. This trend was also true for the Kraft samples and the acid-catalyzed organosolv lignins. The EOS retained a significantly higher content of $\beta$-O-4 linkages, ranging from $24.6 \%$ to $45.8 \%$, as described previously [21]. Therefore, only the acid-catalyzed organosolv lignins are suitable feedstocks for downstream depolymerization. However, the base-catalyzed organosolv lignins are a suitable feedstock for slow pyrolysis, due to the absence of sulfur and the small amount of impurities, such as ash and carbohydrates, as well as low $\mathrm{O} / \mathrm{C}$ ratio, and higher hydrophobicity compared to soda and Kraft lignins [50].

\subsubsection{Thermal Analysis}

As this study aimed to evaluate the valorization potential of the lignin fraction, the thermal processability was investigated, which is crucial for applications such as melt pressing and melt spinning [8]. The thermal properties reflect the molecular features of lignin including rigidity and flexibility that are influenced by inter-/intramolecular hydrogen bonds, degree of cross-linking, and aromaticity, as well as molecular weight distribution [51]. Therefore, the glass transition temperature $\left(T_{g}\right)$ and thermal stability of the lignin fractions were determined via differential scanning calorimetry (DSC) and thermogravimetric analysis (TGA), respectively.

The acid-catalyzed organosolv lignins had the lowest $T_{g} \mathrm{~s}$ (see Table 7, Figure 4), with EOS (-) being the minimum at $393 \mathrm{~K}$. This coincided with the highest content of residual $\beta$-O-4 linkages, lowest amount of free phenolic hydroxyl groups, lowest average molecular weight, and lowest aromaticity (highest $\mathrm{H} / \mathrm{C}$ ratio). As expected, the glass transition temperatures of the base-catalyzed organosolv samples were higher in comparison, ranging from $424 \mathrm{~K}$ to $433 \mathrm{~K}$. No glass transition temperature was detected for both Kraft lignins. This can be attributed to the presence of sulfur (as -SH) and other impurities, high aromaticity, $\mathrm{M}_{w}$ and $\mathrm{OH}_{P h}$, extensive cross-linking, and a low number of ether linkages [51]. The acid-catalyzed organosolv lignins from European larch exhibited slightly lower $T_{g}$ values compared to values reported recently by Rossberg et al. for spruce organosolv lignins, with $393-402 \mathrm{~K}$ versus $\sim 405 \mathrm{~K}$ [8] at distinctly lower average molecular weights, $2.0-2.5 \mathrm{~kg} / \mathrm{mol}$ versus $6.2 \mathrm{~kg} / \mathrm{mol}$ [8]. The thermal stability of the samples was investigated by determining the $5 \%$ mass loss temperature via TGA. The values ranged from $412 \mathrm{~K}$ to $578 \mathrm{~K}$; the comparably low values of the Kraft fraction can be explained due to the presence of impurities such as sulfur (see Figure 5). The better performance of base-catalyzed organosolv lignins $\left(\mathrm{SP}_{2}-\mathrm{SP}_{4}\right)$ compared to the acid-catalyzed lignins originates from the higher degree of condensation and aromaticity of the former [51]. The $\mathrm{T}_{5 \%}$ temperatures were comparable to literature values for organosolv and Kraft lignins of spruce, with 516 K [42] and 536 K [42]/544 K [47], respectively. Note that water/solvent residue from incomplete 
drying during lignin purification can negatively impact $T_{5 \%}$. The high differences between $T_{g}$ and $T_{5 \%}$

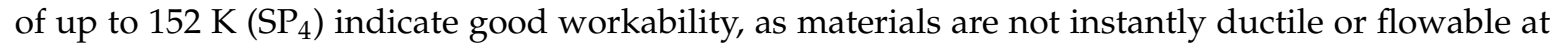
the respective $T_{g}$ but need to be heated further. These findings further demonstrate the promising properties of the base-catalyzed lignin fraction for applications such as additives for composite films and biopolymers [47], feedstock for carbon fiber [8], and adhesive for wood panel production [48].

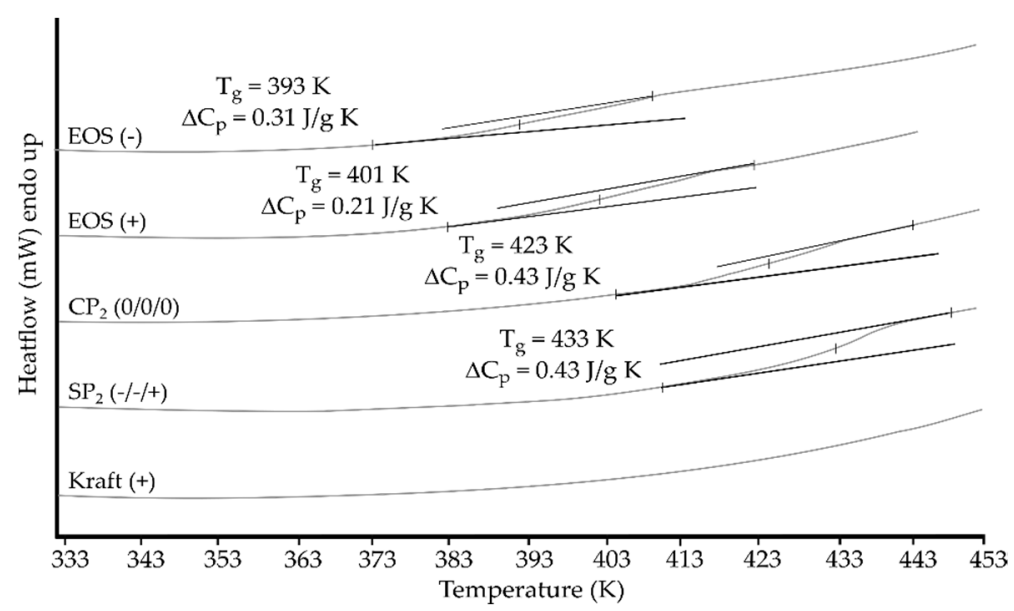

Figure 4. Differential scanning calorimetry (DSC) curves for selected lignin samples. $\triangle \mathrm{CP}$ denotes the change in heat capacity caused by the glass transition.
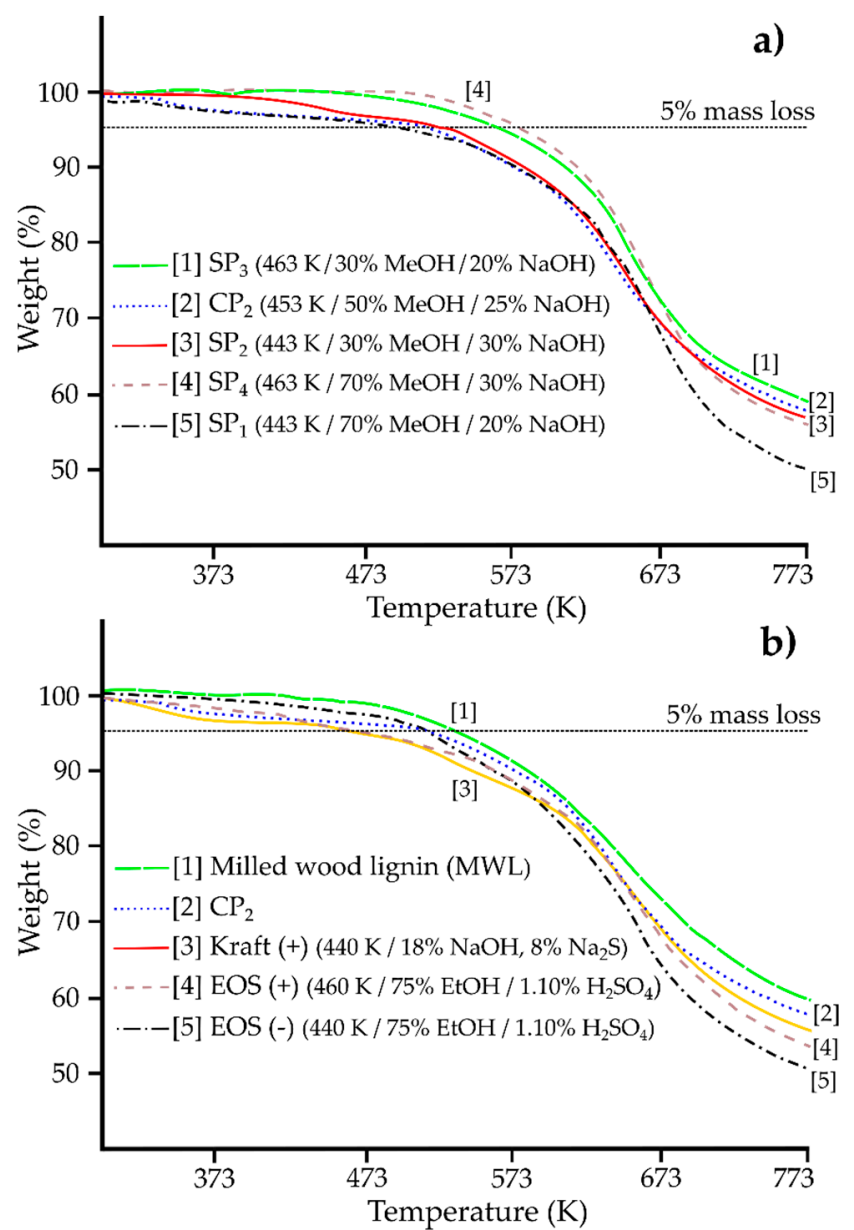

Figure 5. Thermogravimetric analysis (TGA) curves for selected lignin samples. (a) Results for the base-catalyzed organosolv lignins. (b) Results for the milled wood lignin sample, one Kraft, two acid-catalyzed organosolv, and one base-catalyzed organosolv lignin sample again for comparison. 


\section{Materials and Methods}

European sawdust was used as feedstock in this study; the origin, storage conditions, and sampling were described previously [21]. Selected lignin and pulp fractions from this previously reported acid-catalyzed organosolv fractionation using the same feedstock were also analyzed and compared.

\subsection{Base-Catalyzed Organosolv Fractionation}

The reactions were performed in a stirred batch reactor with an internal volume of $0.5 \mathrm{~L}$ (Series 4575A HP/HT, Parr Instrument Company, St. Moline, IL, USA), which was described previously in detail [21]. The used process conditions were based on the Organocell process [12]. As a first step, preliminary fractionation experiments on alcohol-to-water ratio, type of alcohol used, and concentration of base catalyst were performed using a limited set of combinations (see Supplementary Materials). Based on that, a fractional factorial design of experiment was used to investigate the dependence of sugar composition, delignification, lignin yield, and properties on the experimental conditions. The three variables of the $2^{3-1}$ experimental design were reaction temperature $\left(X_{1}\right)$, solvent ratio $\left(X_{2}\right)$, and catalyst concentration $\left(X_{3}\right)$. To reduce the required number of experiments, only a balanced half of the possible variable combinations was used. Four star point $(+/-)$ plus three center point experiments (0) were performed; the latter were carried out to check for curvature and determine reproducibility. The residence time was kept constant at $1 \mathrm{~h}$ at the reaction temperature with a heating rate of 8-10 $\mathrm{K} / \mathrm{min}$, whereas mixing was achieved using a turbine type impeller at $300 \mathrm{rpm}$. Furthermore, the loading of the co-catalyst, as well as the solid-to-liquid ratio, was kept constant at $0.1 \%$ (oven-dried wood, odw) and $8 v / w$, respectively (see Table 8 ).

Table 8. Experimental variables for the base catalyzed organosolv process.

\begin{tabular}{ccccc}
\hline Variable & Assignment & $\mathbf{( - )}$ & $\mathbf{( 0 )}$ & $\mathbf{( + )}$ \\
\hline $\mathrm{X}_{1}$ & Temperature $(\mathrm{K})$ & 443 & 453 & 463 \\
$\mathrm{X}_{2}$ & Methanol $(\mathrm{MeOH}) / \mathrm{H}_{2} \mathrm{O}(v / v)$ & $30: 70$ & $50: 50$ & $70: 30$ \\
$\mathrm{X}_{3}$ & $\mathrm{NaOH}\left(w / w\right.$ odw $\left.^{\mathrm{a}}\right)$ & 20 & 25 & 30 \\
\hline \multicolumn{5}{c}{${ }^{\mathrm{a}}$ odw, oven-dried wood. }
\end{tabular}

In detail, for each run, a fresh methanol (99.9\%, Fischer Scientific, Schwerte, Germany)/water mixture was prepared. The required amount of $\mathrm{NaOH}(\geq 99 \%$, VRW Chemicals, Germany) was then dissolved in the solution and left to cool down to room temperature. Then, $250 \mathrm{~mL}$ of this solution was combined with $32 \mathrm{~g}$ of sawdust (odw) and $32 \mathrm{mg}$ of anthraquinone (97\%, Sigma Aldrich, Steinheim, Germany) as co-catalyst in the reactor. After the desired reaction time elapsed, the ceramic heater was removed, and the pulping liquor was cooled down via internal cooling loop to $323 \mathrm{~K}$ at an average rate of $6 \mathrm{~K} / \mathrm{min}$. The pulping liquor was then filtered in a Büchner funnel with a Whatman No. 5 filter paper to separate the cellulose-rich pulp fraction from the lignin- and hemicellulose-containing liquid fraction. The pulp was washed three times with $65 \mathrm{~mL}$ of warm $(323 \mathrm{~K})$ aqueous $\mathrm{MeOH}$ with identical solvent ratio to the pulping liquor, followed by three washes with warm ( $323 \mathrm{~K})$ water ( $65 \mathrm{~mL}$ each), which was combined with the initial filtrate. The washed pulp fraction was then transferred to a $500-\mathrm{mL}$ round-bottom flask and freeze-dried for $40 \mathrm{~h}$. To ease the consequent lignin precipitation, the methanol content in the combined liquor was diluted to roughly $20 \% v / v$ via water addition. Then, concentrated $\mathrm{HCl}$ (37\%, Merck, Darmstadt, Germany) was added dropwise under constant stirring until a pH of 3.5 was reached, which was monitored with a $\mathrm{pH}$ meter (Metrohm 691, Metrohm, Herisau, Switzerland). To be able to isolate the lignin fraction, the resulting suspension was centrifuged at $12,000 \times g$ for 20 $\mathrm{min}$, and the supernatant liquid was decanted, filtered, and stored for analysis. The lignin fraction was resuspended in deionized $\mathrm{H}_{2} \mathrm{O}$, thoroughly mixed, ultrasonicated of $5 \mathrm{~min}$, and centrifuged, which was repeated once, before freeze-drying for $40 \mathrm{~h}$ in a $250 \mathrm{~mL}$ round-bottom flask (see Figure 6). 


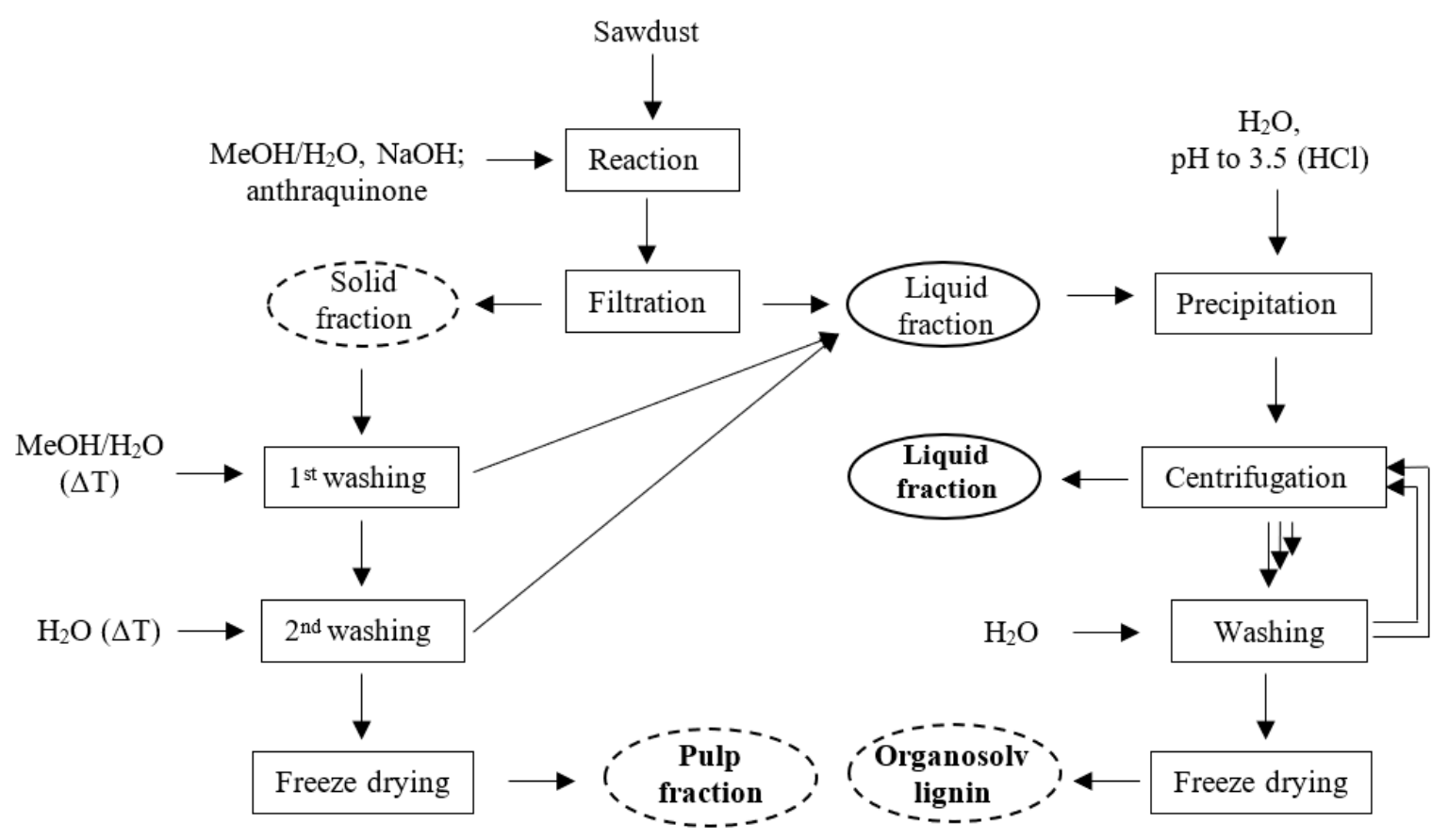

Figure 6. Reaction scheme for the base-catalyzed organosolv fractionation including the work-up procedure. Product fractions are written in bold, and dashed lines indicate solid fractions, whereas solid lines indicate liquid fractions (modified from a previous study by the authors [21]).

\subsection{Data Analysis}

To determine the significant factors and their influence on process yield and pulp and lignin characteristics, Design-Expert software for Windows (version 12, 2019, Stat-Ease Inc, Minneapolis, MN, USA) was used. The Shapiro-Wilk test was used to for normality, while ANOVA analysis and multiple linear regression were used to determine the effects of the factors on the responses [24].

\subsection{Lab-Scale Kraft Pulping}

As reference for the fractionation processes, two different lab-scale Kraft cooks were performed, based on conditions published by Hörhammer et al. [30]. A low-severity process and a high-severity process were chosen, according to both $\mathrm{H}$-factor and catalyst/co-catalyst loading. The $\mathrm{H}$-factor combines both temperature and time into a single factor; however, it does not account for catalyst dosage [52]. For both cooks, the liquid-to-solid ratio, reaction temperature, heating time, and stirring speed were kept constant at $3.5 \mathrm{v} / \mathrm{w}, 440 \mathrm{~K}, 15 \mathrm{~min}$ and $300 \mathrm{rpm}$, respectively. Then, $40 \mathrm{~g}$ of sawdust on a dry wood basis was loaded into the reactor with $140 \mathrm{~mL}$ of deionized $\mathrm{H}_{2} \mathrm{O}$, containing the desired amount of $\mathrm{NaOH}$ and $\mathrm{Na}_{2} \mathrm{~S}$ ( $\geq 60 \%$, Sigma Aldrich, Steinheim, Germany) (see Table 9). The work-up procedure was performed similarly to the base-catalyzed organosolv processes (see Figure 6), with some modifications. Firstly, the pulp fraction was washed with five times with $65 \mathrm{~mL}$ of warm (323 $\mathrm{K})$ water. Secondly, the lignin fraction was washed with water acidified to $\mathrm{pH} 3.5$, using acetic acid ( $\geq 99 \%$, Merck, Darmstadt, Germany), to remove excess sulfur as $\mathrm{H}_{2} \mathrm{~S}$.

Table 9. Experimental conditions of the low- and high-severity Kraft cooks (liquid-to-wood ratio 3.5, heat-up/cooldown time of $15 \mathrm{~min}, 440 \mathrm{~K}$ ).

\begin{tabular}{ccc}
\hline Parameter & Low & High \\
\hline Reaction time, min & 58 & 134 \\
H-factor, $\mathrm{h}$ & 850 & 1650 \\
$\mathrm{NaOH}, \%($ odw) & 15.0 & 17.7 \\
$\mathrm{Na}_{2} \mathrm{~S}, \%$ (odw) & 5.76 & 7.61 \\
\hline
\end{tabular}




\subsection{Crude Milled Wood Lignin (MWLc) Preparation}

Firstly, $20 \mathrm{~g}$ of European larch sawdust was milled to a fraction $<60$ mesh and extracted with acetone in a Soxhlet apparatus for $16 \mathrm{~h}$ at $\geq 6$ cycles per hour with $300 \mathrm{~mL}$ of solvent prior to MWL preparation. The crude milled wood lignin was prepared based on a method described by Zinovyev et al. [53]. In detail, $4 \mathrm{~g}$ of extracted sawdust was milled in a $250-\mathrm{mL} \mathrm{ZrO}_{2}$ bowl, with $34 \mathrm{ZrO}_{2}$ balls $(\varnothing 5 \mathrm{~mm}$ ) in a planetary ball mill (Pulverisette 6, Fritsch, Idar-Oberstein, Germany). The milling was performed at $500 \mathrm{rpm}$ with $30 \mathrm{~min}$ of milling followed by $15 \mathrm{~min}$ of pause, to avoid excess heating, for a total of 15 cycles. The whole procedure was performed three times. Then, $11.2 \mathrm{~g}$ of fine wood meal was subjected to a fourfold aqueous dioxane $(96 \% v / v)(\geq 99.5 \%$, Sigma Aldrich, Steinheim, Germany) extraction. For this, $2.81 \mathrm{~g}$ of wood meal was mixed with $39.3 \mathrm{~mL}$ of solvent in separate 50-mL centrifuge tubes (Greiner, Sigma Aldrich, Steinheim, Germany) and shaken constantly for $24 \mathrm{~h}$ in the absence of light. Afterward, the suspensions were centrifuged at $3000 \times g$ for $10 \mathrm{~min}$ (Centrifuge 5702, Eppendorf, Wesseling-Berzdorf, Germany) to easily decant the supernatant solution, which was combined in a single flask and stored at $4{ }^{\circ} \mathrm{C}$. This procedure was repeated four times, and the combined solution was filtered in a Büchner funnel with Whatman No. 5 filter paper (Sigma Aldrich, Vienna, Austria), and the solvent removed under vacuum at $35^{\circ} \mathrm{C}$. The solid matter was resuspended in $100 \mathrm{~mL}$ of water, ultrasonicated for $15 \mathrm{~min}$, and freeze-dried for $40 \mathrm{~h}$ to remove traces of both dioxane and water. The yield of the crude milled wood lignin was $0.78 \mathrm{~g}$, corresponding to $26 \%$ of the total lignin content.

\subsection{Milled Wood Lignin Purification}

To remove residual carbohydrates, which impede the quantitative determination of structural features, a purification according to Björkman et al. [54] was performed. In detail, the crude MWL was firstly dissolved in $20 \mathrm{~mL} / \mathrm{g} \mathrm{90 \%} \mathrm{v/v} \mathrm{acetic} \mathrm{acid} \mathrm{(} \geq 99 \%$, Merck, Darmstadt, Germany) and then added dropwise to $230 \mathrm{~mL} / \mathrm{g}$ DI water under constant stirring. The suspension was then centrifuged at $12,000 \times g$ for $20 \mathrm{~min}$ (CR $22 \mathrm{~N}$, Hitachi, Tokyo, Japan), the supernatant solution was discarded, and the solid matter was freeze-dried for $48 \mathrm{~h}$. As the last step, the dried lignin phase was dissolved in a 20 $\mathrm{mL} / \mathrm{g}$ 2:1 mixture of 1,2-dichloroethane ( $\geq 99.8 \%$, Sigma Aldrich, Steinheim, Germany) and ethanol ( $\geq 99.5 \%$, Merck, Darmstadt, Germany), before being filtered and precipitated in $230 \mathrm{~mL} / \mathrm{g}$ petrol ether (extra pure, Carl ROTH, Karlsruhe, Germany). The insoluble fraction was separated via filtration, washed three times with $20 \mathrm{~mL}$ of fresh petrol ether, and dried in vacuo overnight to yield the purified milled wood lignin (MWL).

\subsection{Lignin Purification}

To remove residual carbohydrates and extractives, catalyst, and cocatalyst, which all interfere with follow-up lignin analyses, approximately $3.5 \mathrm{~g}$ of the raw lignin fractions from the base-catalyzed organosolv and Kraft fractionations were purified according to milled wood lignin protocol (see above).

\subsection{Analysis of Chemical Composition}

The composition of the feedstock, pulp, and lignin fractions was analyzed according to Sluiter et al. [22] using a two-step hydrolysis method. In detail, as the first step, the pulp sample was hydrolyzed in $72 \% w / w \mathrm{H}_{2} \mathrm{SO}_{4}$, at an acid-to-pulp ratio of $10 \mathrm{~mL} / \mathrm{g}$, at $303 \mathrm{~K}$, for $1 \mathrm{~h}$. The resulting suspension was subjected to the second hydrolysis in $4 \% w / w \mathrm{H}_{2} \mathrm{SO}_{4}$, with an acid-to-pulp ratio of $300 \mathrm{~mL} / \mathrm{g}$, in an autoclave at $394 \pm 1 \mathrm{~K}$, for $1 \mathrm{~h}$. After filtration using a glass frit (porosity 4 ), the acid-insoluble (Klason) lignin was determined gravimetrically, while the content of acid-soluble lignin (ASL) was determined by measuring the absorbance at $205 \mathrm{~nm}$ (spectrophotometer Shimadzu UV-2550), using $110 \mathrm{~L} /(\mathrm{g} \cdot \mathrm{cm}$ ) as the extinction coefficient. The monosaccharides were determined via high-performance anion exchange chromatography (HPAEC-PAD) in a Dionex ICS-3000 system, equipped with a CarboPac 
PA20 column. The hemicellulose and cellulose content of European larch sawdust and the resulting pulp fractions were calculated according to the Janson formulas [55].

\subsection{Thermal Analysis}

To determine thermal stability and processability of the purified lignin fractions, thermal analyses were performed. Thermogravimetric analysis (TGA) was carried out on a STA $449 \mathrm{C}$ Jupiter thermal analyzer (NETZCH, Selb, Germany). Here, 2-3 mg of sample was placed into an aluminum pan crucible, and the temperature range was set to 293 to $823 \mathrm{~K}$ at a heating rate of $10 \mathrm{~K} / \mathrm{min}$ with a 15 -min holding time at maximum temperature. Helium was used as the purge gas with a flow rate of 50 $\mathrm{cm}^{3} / \mathrm{min}$. Differential scanning calorimetry (DSC) was performed on a DSC 8500 (Perkin Elmer Rodgau, Germany) with a temperature range from 273 to $453 \mathrm{~K}$ at a heating rate of $20 \mathrm{~K} / \mathrm{min}$. The analysis was carried out under nitrogen atmosphere, with a flow rate of $20 \mathrm{~cm}^{3} / \mathrm{min}$ and $8-10 \mathrm{mg}$ per sample. Glass transition temperatures $\left(T_{g}\right)$ from the second heating run were interpreted as the midpoint of change in heat capacity

\subsection{Further Analysis Techniques}

The methods below were described in detail in a previous publication [21] and, thus, are only briefly mentioned here.

The phenolic $\left(\mathrm{OH}_{\mathrm{Ph}}\right)$ and aliphatic hydroxyl $\left(\mathrm{OH}_{\mathrm{Alk}}\right)$ groups, as well as carboxyl groups $(\mathrm{COOH})$, were determined via ${ }^{31} \mathrm{P}-\mathrm{NMR}$ analysis on a Bruker Biospin Avance III $400 \mathrm{MHz}$ spectrometer (Bruker, Billerica, MA, USA) using cyclohexanol as the internal standard and chromium(III) acetylacetonate as the relaxation agent.

The number of residual $\beta$-O-4 linkages was determined via thioacidolysis GC/MS on a Saturn 2100 (Varian, Agilent, Palo Alto, CA, USA) equipped with a poly(dimethylsiloxane) column (30 m $\times 0.25$ mm; PB-1, Supelco, Sigma Aldrich, St. Louis, MO, USA) with heneicosane (C21H44, Fluka Analytical, Darmstadt USA) as the internal standard.

The molecular weight of the lignin fractions was estimated via HPLC-SEC-UV using a styrene-divinylbenzene PLgel column ( $5 \mathrm{~mm}, 100 \AA$, $600 \mathrm{~mm}$ length, $7.5 \mathrm{~mm}$ inner diameter, Agilent, Polymer Laboratories, Palo Alto, CA) with a photodiode array detector (Dionex Ultimate 3000 UV/VIS detector) and propylene oxide standards (Igepal, Sigma Aldrich Steinheim, Germany ).

\section{Conclusions}

In this study, for the first time, a comprehensive analysis of fractionation performance and the influence of pulping conditions on lignin properties of a $\mathrm{NaOH} /$ anthraquinone-catalyzed organosolv fractionation of softwood was discussed. This study should also serve as the step stone for future valorization of European larch sawdust, and it demonstrated that lignins with promising physicochemical properties can be isolated.

The most promising fractionation conditions, $443 \mathrm{~K}, 30 \% v / v \mathrm{MeOH}, 30 \% w / w \mathrm{NaOH}$, achieved a cellulose recovery of $89 \%$ and a delignification efficiency of $91 \%$. The pure lignin yield was $82 \%$ with a residual carbohydrate content of $2.98 \% w / w$ and $1.24 \% w / w$ ash. The high purity and high aromaticity, on the one hand, make the lignin fractions good feedstocks for carbon fibers or slow pyrolysis. Furthermore, the high contents of phenolic hydroxyl and carboxyl groups, together with low molecular weight and promising thermal properties (low $T_{g}$ with high $T_{5 \%}$ ), indicate good usability as feedstock for biopolymer synthesis and as an additive in composite films and in wood panels.

Further investigations on larch wood sawdust and the isolated lignin fractions are planned to fully assess the potential of the feedstock and its fractionation products. As a next step, a green fractionation technique, $\gamma$-valerolactone pulping, will be investigated and compared. Additional analysis techniques are also planned such as zeta potential, two-dimensional (2D) HSQC NMR, and quantitative ${ }^{13} \mathrm{C}-\mathrm{NMR}$ analysis. 
Supplementary Materials: The following are available online at http://www.mdpi.com/2073-4344/9/12/996/s1: Table S1: A detailed description of the preliminary experiments; Table S2: The results of Shapiro-Wilk test for normality; Tables S3-S7: ANOVA analysis for the responses of the fractional factorial design; Tables S8-S12: Results from multilinear regression analyses of the responses; Table S13: Detailed results from the thioacidolysis GC/MS experiments.

Author Contributions: M.H. designed the experiments and wrote the manuscript; M.H., G.T., B.C.-B., L.C., and A.M. performed the experimental analyses; B.C.-B., G.T., M.M., and S.S. critically reviewed the manuscript; M.M. and S.S. provided supervision throughout the study.

Funding: This research received no external funding.

Acknowledgments: The authors would like to thank Herbert Sixta for his suggestions, as well as Quang Lê Hui and Rita Hatakka for their expertise in determining the feedstock composition; as the authors also thank Josefine Hobisch for her help with DSC/TGA analyses. Furthermore, the authors acknowledge the Open Access Funding by the University of Graz.

Conflicts of Interest: The authors declare no conflict of interest.

\section{References}

1. Biomass Fractionation Technologies for a Lignocellulosic Feedstock Based Biorefinery; Mussatto, S.I. (Ed.) Elsevier: Amsterdam, The Netherlands, 2016; ISBN 9780128023235.

2. Rinaldi, R.; Jastrzebski, R.; Clough, M.T.; Ralph, J.; Kennema, M.; Bruijnincx, P.C.A.; Weckhuysen, B.M. Paving the way for lignin valorisation: Recent advances in bioengineering, biorefining and catalysis. Angew. Chem. Int. Ed. Engl. 2016, 55, 8164-8215. [CrossRef] [PubMed]

3. Nitsos, C.; Rova, U.; Christakopoulos, P. Organosolv fractionation of softwood biomass for biofuel and biorefinery applications. Energies 2018, 11, 50. [CrossRef]

4. Kleinert, T.; Tayenthal, K.v. Über neuere Versuche zur Trennung von Cellulose und Inkrusten verschiedener Hölzer. Angew. Chem. 1931, 44, 788-791. [CrossRef]

5. Rodríguez, A.; Espinosa, E.; Domínguez-Robles, J.; Sánchez, R.; Bascón, I.; Rosal, A. Different solvents for organosolv pulping. In Pulp and Paper Processing; Kazi, S.N., Ed.; InTechOpen: London, United Kingdom, 2018; ISBN 978-1-78923-847-1.

6. Sixta, H. Handbook of Pulp; Wiley-VCH: Weinheim, Germany, 2006; ISBN 9783527309979.

7. Løhre, C.; Kleinert, M.; Barth, T. Organosolv extraction of softwood combined with lignin-to-liquid-solvolysis as a semi-continuous percolation reactor. Biomass Bioenergy 2017, 99, 147-155. [CrossRef]

8. Rossberg, C.; Janzon, R.; Saake, B.; Leschinsky, M. Effect of process parameters in pilot scale operation on properties of organosolv lignin. Bioresources 2019, 14. [CrossRef]

9. Nitsos, C.; Stoklosa, R.; Karnaouri, A.; Vörös, D.; Lange, H.; Hodge, D.; Crestini, C.; Rova, U.; Christakopoulos, P. Isolation and characterization of organosolv and alkaline lignins from hardwood and softwood biomass. ACS Sustain. Chem. Eng. 2016, 4, 5181-5193. [CrossRef]

10. Imlauer-Vedoya, C.M.; Vergara-Alarcón, P.; Area, M.C.; Revilla, E.; Felissia, F.E.; Villar, J.C. Fractionation of Pinus radiata wood by combination of steam explosion and organosolv delignification. Maderas. Cienc. Tecnol. 2019, 21, 587-598. [CrossRef]

11. Lesar, B.; Humar, M.; Hora, G.; Hachmeister, P.; Schmiedl, D.; Pindel, E.; Siika-aho, M.; Liitiä, T. Utilization of recycled wood in biorefineries: Preliminary results of steam explosion and ethanol/water organosolv pulping without a catalyst. Eur. J. Wood Prod. 2016, 74, 711-723. [CrossRef]

12. Baumeister, M.; Edel, E. Äthanol-Wasser-Aufschluss. Das Papier 1980, 34, V9-V18.

13. Schröter, M.C. Possible lignin reaction in the organocell pulping process. Tappi J. 1991, 73, 197-200.

14. Fullerton, T.J. Soda-anthraquinone pulping. The advantages of using oxygen-free conditions. Tappi J. 1979, $62,55-57$.

15. Lindner, A.; Wegener, G. Characterization of lignins from organosolv pulping according to the organocell process. Part 1. Elemental analysis, nonlignin portions and functional groups. J. Wood Chem. Technol. 1988, 8, 323-340. [CrossRef]

16. Lindner, A.; Wegener, G. Characterization of lignins from organosolv pulping according to the organocell process. Part 2. Residual lignins. J. Wood Chem. Technol. 1989, 9, 443-465. [CrossRef] 
17. Lindner, A.; Wegener, G. Characterization of lignins from organosolv pulping according to the organocell process. Part 3. Permanganate oxidation and thioacidolysis. J. Wood Chem. Technol. 1990, 10, 331-350. [CrossRef]

18. Lindner, A.; Wegener, G. Characterization of lignins from organosolv pulping according to the organocell process. Part 4. Molecular weight determination and investigation of fractions isolated by GPC. J. Wood Chem. Technol. 1990, 10, 351-363. [CrossRef]

19. Da Ronch, F.; Caudullo, G.; Tinner, W.; de Rigo, D. Larix decidua and other larches in Europe: Distribution, habitat, usage and threats. In European Atlas of Forest Tree Species, 2016th ed.; San-Miguel-Ayanz, J., de Rigo, D., Caudullo, G., Durrant, T.H., Mauri, A., Eds.; Publication Office of the European Union: Luxembourg, 2016; ISBN 978-92-79-36740-3.

20. Crestini, C.; Lange, H.; Sette, M.; Argyropoulos, D.S. On the structure of softwood Kraft lignin. Green Chem. 2017, 19, 4104-4121. [CrossRef]

21. Hochegger, M.; Cottyn-Boitte, B.; Cézard, L.; Schober, S.; Mittelbach, M. Influence of ethanol organosolv pulping conditions on physicochemical lignin properties of European larch. Int. J. Chem. Eng. 2019, 2019, 1-10. [CrossRef]

22. Sluiter, A.; Hames, B.; Ruiz, R.; Scarlata, C.; Sluiter, J.; Templeton, D.; Crocker, D. Determination of Structural Carbohydrates and Lignin in Biomass. Technical Report NREL/TP-510-42618; 2012. Available online: https://www.nrel.gov/docs/gen/fy13/42618.pdf (accessed on 26 November 2019).

23. Sjöström, E. Wood Chemistry. Fundamentals and Applications, 2nd ed.; Academic Press: San Diego, CA, USA, 1993; ISBN 9780126474817.

24. Carlson, R.; Carlson, J.E. Design and Optimization in Organic Synthesis, 2nd ed.; Elsevier: Amsterdam, The Netherlands, 2005; ISBN 9780080455273.

25. Tran, A. Effect of cooking temperature on Kraft pulping of hardwood. Tappi J. 2002, 1, 13-19.

26. Yang, R.; Lucia, L.; Ragauskas, A.; Jameel, H. Oxygen delignification chemistry and its impact on pulp fibers. J. Wood Chem. Technol. 2003, 23, 13-29. [CrossRef]

27. Borrega, M.; Larsson, P.T.; Ahvenainen, P.; Ceccherini, S.; Maloney, T.; Rautkari, L.; Sixta, H. Birch wood pre-hydrolysis vs pulp post-hydrolysis for the production of xylan-based compounds and cellulose for viscose application. Carbohydr. Polym. 2018, 190, 212-221. [CrossRef]

28. Ehman, N.; Tarrés, Q.; Delgado-Aguilar, M.; Vallejos, M.; Felissia, F.; Area, M.; Mutjé, P. From pine sawdust to cellulose nanofibres. Cell Chem. Technol. 2016, 50, 361-367.

29. Liu, J.; Korpinen, R.; Mikkonen, K.S.; Willför, S.; Xu, C. Nanofibrillated cellulose originated from birch sawdust after sequential extractions: A promising polymeric material from waste to films. Cellulose 2014, 21, 2587-2598. [CrossRef]

30. Hörhammer, H. A Larch Biorefinery Producing Pulp and Lactic Acid. Ph.D. Thesis, Aalto University, Espoo, Finland, 2014.

31. McDonough, T.J. The chemistry of organosolv delignification. Tappi J. 1993, 76, 186-193.

32. Hu, F.; Jung, S.; Ragauskas, A. Pseudo-lignin formation and its impact on enzymatic hydrolysis. Bioresour. Technol. 2012, 117, 7-12. [CrossRef] [PubMed]

33. Shinde, S.D.; Meng, X.; Kumar, R.; Ragauskas, A.J. Recent advances in understanding the pseudo-lignin formation in a lignocellulosic biorefinery. Green Chem. 2018, 20, 2192-2205. [CrossRef]

34. Burkhardt, S.; Kumar, L.; Chandra, R.; Saddler, J. How effective are traditional methods of compositional analysis in providing an accurate material balance for a range of softwood derived residues? Biotechnol. Biofuels 2013, 6, 90. [CrossRef]

35. Baumberger, S.; Abaecherli, A.; Fasching, M.; Gellerstedt, G.; Gosselink, R.; Hortling, B.; Li, J.; Saake, B.; de Jong, E. Molar mass determination of lignins by size-exclusion chromatography: Towards standardisation of the method. Holzforschung 2007, 61, 205. [CrossRef]

36. Gosselink, R.J.A.; Abächerli, A.; Semke, H.; Malherbe, R.; Käuper, P.; Nadif, A.; van Dam, J.E.G. Analytical protocols for characterisation of sulphur-free lignin. Ind. Crops Prod. 2004, 19, 271-281. [CrossRef]

37. Bauer, S.; Sorek, H.; Mitchell, V.D.; Ibáñez, A.B.; Wemmer, D.E. Characterization of miscanthus giganteus lignin isolated by ethanol organosolv process under reflux condition. J. Agric. Food Chem. 2012, 60, 8203-8212. [CrossRef] 
38. Constant, S.; Wienk, H.L.J.; Frissen, A.E.; Peinder, P.D.; Boelens, R.; van Es, D.S.; Grisel, R.J.H.; Weckhuysen, B.M.; Huijgen, W.J.J.; Gosselink, R.J.A.; et al. New insights into the structure and composition of technical lignins: A comparative characterisation study. Green Chem. 2016, 18, 2651-2665. [CrossRef]

39. Zhu, M.-Q.; Wen, J.-L.; Su, Y.-Q.; Wei, Q.; Sun, R.-C. Effect of structural changes of lignin during the autohydrolysis and organosolv pretreatment on Eucommia ulmoides Oliver for an effective enzymatic hydrolysis. Bioresour. Technol. 2015, 185, 378-385. [CrossRef]

40. Gilarranz, M.A.; Rodríguez, F.; Oliet, M. Lignin behavior during the autocatalyzed methanol pulping of eucalyptus globulus changes in molecular weight and functionality. Holzforschung 2000, 54, 373-380. [CrossRef]

41. Pan, X.; Kadla, J.F.; Ehara, K.; Gilkes, N.; Saddler, J.N. Organosolv ethanol lignin from hybrid poplar as a radical scavenger: Relationship between lignin structure, extraction conditions, and antioxidant activity. J. Agric. Food Chem. 2006, 54, 5806-5813. [CrossRef] [PubMed]

42. Gordobil, O.; Moriana, R.; Zhang, L.; Labidi, J.; Sevastyanova, O. Assesment of technical lignins for uses in biofuels and biomaterials: Structure-related properties, proximate analysis and chemical modification. Ind. Crops Prod. 2016, 83, 155-165. [CrossRef]

43. Argyropoulos, D.S. 31P NMR in wood chemistry: A review of recent progress. Res. Chem. Intermed. 1995, 21, 373. [CrossRef]

44. Balakshin, M.; Capanema, E. On the quantification of lignin hydroxyl groups with 31P and 13C NMR spectroscopy. J. Wood Chem. Technol. 2015, 35, 220-237. [CrossRef]

45. Yang, X.; Li, N.; Lin, X.; Pan, X.; Zhou, Y. Selective cleavage of the aryl ether bonds in lignin for depolymerization by acidic lithium bromide molten salt hydrate under mild conditions. J. Agric. Food Chem. 2016, 64, 8379-8387. [CrossRef]

46. Lai, C.; Tu, M.; Shi, Z.; Zheng, K.; Olmos, L.G.; Yu, S. Contrasting effects of hardwood and softwood organosolv lignins on enzymatic hydrolysis of lignocellulose. Bioresour. Technol. 2014, 163, 320-327. [CrossRef]

47. Zhao, Y.; Tagami, A.; Dobele, G.; Lindström, M.E.; Sevastyanova, O. The impact of lignin structural diversity on performance of cellulose nanofiber (CNF)-starch composite films. Polymers 2019, 11, 538. [CrossRef]

48. Koumba-Yoya, G.; Stevanovic, T. Study of organosolv lignins as adhesives in wood panel production. Polymers 2017, 9, 46. [CrossRef]

49. Huang, F.; Singh, P.M.; Ragauskas, A.J. Characterization of milled wood lignin (MWL) in loblolly pine stem wood, residue, and bark. J. Agric. Food Chem. 2011, 59, 12910-12916. [CrossRef] [PubMed]

50. Toloue Farrokh, N.; Suopajärvi, H.; Mattila, O.; Umeki, K.; Phounglamcheik, A.; Romar, H.; Sulasalmi, P.; Fabritius, T. Slow pyrolysis of by-product lignin from wood-based ethanol production-A detailed analysis of the produced chars. Energy 2018, 164, 112-123. [CrossRef]

51. Kubo, S.; Kadla, J.F. Poly(ethylene oxide)/organosolv lignin blends: Relationship between thermal properties, chemical structure, and blend behavior. Macromolecules 2004, 37, 6904-6911. [CrossRef]

52. Vroom, K.E. The $\mathrm{H}$ factor: A means of expressing cooking times and temperatures as a single variable. Pulp Paper Mag. Can. 1957, 58, 228-231.

53. Zinovyev, G.; Sumerskii, I.; Rosenau, T.; Balakshin, M.; Potthast, A. Ball milling's effect on pine milled wood lignin's structure and molar mass. Molecules 2018, 23, 2223. [CrossRef]

54. Björkman, A. Studies on finely divided wood. Part 1. Extraction of lignin with neutral solvents. Sven Papperstidn 1956, 59, 477-485.

55. Janson, J. Calculation of the polysaccharide composition of wood and pulp. Paperi Ja Puu 1970, 52, $323-329$.

(C) 2019 by the authors. Licensee MDPI, Basel, Switzerland. This article is an open access article distributed under the terms and conditions of the Creative Commons Attribution (CC BY) license (http://creativecommons.org/licenses/by/4.0/). 